\title{
Desmídias perifíticas de cinco lagoas do Distrito Federal, Brasil: II - Gêneros Euastrum Ehrenberg ex Ralfs, Micrasterias C. Agardh ex Ralfs e Triploceras Bailey
}

\author{
Bárbara Medeiros Fonseca ${ }^{1,3}$ e Lillian Mércia Benevenuto Estrela ${ }^{1,2}$
}

Recebido: 17.10.2014; aceito: 18.03.2015

\begin{abstract}
Periphytic desmids from five lagoons of the Federal District, Brazil: II - Genera Euastrum Ehrenberg ex Ralfs, Micrasterias C. Agardh ex Ralfs, and Triploceras Bailey). This study aimed at doing a taxonomic survey on the genera Euastrum, Micrasterias, and Triploceras in five oligotrophic lagoons in the Federal District, Brazil: Lagoa Bonita, Lagoa Joaquim Medeiros, Lagoa do Cedro, Lagoa Taquara, and Lagoa dos Gansos. Samples were taken between 2006 and 2009, by squeezing macrophytes and/or scraping submerged substrates; 15 samples were analyzed and deposited at the Herbarium of the University of Brasilia. They were fixed in formalin solution (4\%) and analyzed under $400 \times$ and $1000 \times$ magnification. This study reported 13 taxa of Euastrum, 11 of Micrasterias, and one of Triploceras. Among them, 12 are cited for the first time in the Federal District (nine Euastrum and three Micrasterias). Lagoa dos Gansos had the highest number of taxa (14). Euastrum brasiliense var. brasiliense Borge was the most common taxon.
\end{abstract}

Keywords: algae, Brasília, Cerrado, periphyton, Zygnemaphyceae

RESUMO - (Desmídias perifíticas de cinco lagoas do Distrito Federal, Brasil: II - Gêneros Euastrum Ehrenberg ex Ralfs, Micrasterias C. Agardh ex Ralfs e Triploceras Bailey). Este estudo teve como objetivo realizar o levantamento taxonômico dos gêneros Euastrum, Micrasterias e Triploceras de cinco lagoas oligotróficas do Distrito Federal: Lagoa Bonita, Lagoa Joaquim Medeiros, Lagoa do Cedro, Lagoa Taquara e Lagoa dos Gansos. As coletas foram realizadas entre 2006 e 2009, por meio do espremido de macrófitas e/ou raspagem de substratos submersos, num total de 18 amostras depositadas no Herbário da Universidade de Brasília. O material coletado foi fixado em formalina a 4\% e analisado sob aumentos de $400 \times \mathrm{x}$ e 1000×. Este estudo registrou 13 táxons de Euastrum, onze de Micrasterias e um de Triploceras. Desses, 12 são citações pioneiras para o Distrito Federal (nove Euastrum e três Micrasterias). A Lagoa dos Gansos se destacou pela maior riqueza entre as lagoas. Euastrum brasiliense var. brasiliense Borge foi o táxon mais comum.

Palavras-chave: algas, Brasília, Cerrado, perifíton, Zygnemaphyceae

\section{Introdução}

Os gêneros Euastrum Ehrenberg ex Ralfs e Micrasterias C. Agardh ex Ralfs são desmídias cosmopolitas conhecidas por apresentarem certa sobreposição de características morfológicas em algumas de suas espécies (juntamente com Cosmarium Corda ex Ralfs). Em relação a Triploceras Bailey, embora morfologicamente este gênero seja bem distinto de Euastrum e Micrasterias, estudos recentes apontam evidências moleculares de proximidades filogenéticas da espécie $T$. gracile Bailey com alguns táxons de Micrasterias (Škaloud et al. 2011). Todos estão classificados atualmente no grande grupo das estreptófitas, o qual inclui, além das desmídias, outras algas verdes filogeneticamente próximas das plantas terrestres, como as macroalgas do grupo das carofíceas (Leliaert et al. 2012).

No Brasil, entre os trabalhos taxonômicos recentes publicados sobre os gêneros acima estão Melo et al. (2009), sobre Euastrum e Micrasterias da ambientes amazônicos, e Oliveira et al. (2009), sobre Micrasterias de áreas de proteção ambiental do Estado da Bahia. Triploceras, por sua vez, foi registrado

1. Universidade Católica de Brasília, Curso de Ciências Biológicas, Sala E-10, QS 07, Lote 01, Águas Claras, 71966-700, Taguatinga, DF, Brasil

2. Parte do Trabalho de Conclusão de Curso desta Autora.

3. Autor para correspondência: barbara.fonseca0603@gmail.com 
no estudo de Oliveira et al. (2014), também em amostras do Estado da Bahia. Apesar de mais antigos, destacam-se também levantamentos florísticos amplos como os de Förster $(1964,1969,1974)$.

Considerando o Distrito Federal, as informações sobre desmídias encontram-se em relatórios, teses e dissertações (Cronberg 1977, Giani 1984, Leite 1990, Murakami 2000, Abreu 2001, Oliveira 2004, Mendonça-Galvão 2005, Gomes 2007, Philomeno 2007), a maioria sem descrições ou ilustrações. Os poucos estudos publicados que fazem referência a algum dos gêneros considerados neste estudo são os trabalhos ecológicos de Oliveira \& Krau (1970) e Giani \& Pinto Coelho (1986), realizados no Lago Paranoá. Estrela et al. (2011) abordou o gênero Cosmarium Corda em amostras de perifíton das mesmas lagoas consideradas no presente estudo. Neste sentido, tem-se como objetivo dar continuidade ao trabalho citado, desta vez focando-se os gêneros Euastrum, Micrasterias e Triploceras, trazendo-se uma revisão sobre esses táxons na região.

\section{Material e métodos}

As coletas foram feitas nos seguintes locais: Lagoa Bonita (15³5'22,4"S; 4741'49,0"O), Lagoa Joaquim Medeiros (153' $\left.15,9^{\prime \prime} \mathrm{S} ; 47^{\circ} 41^{\prime} 29,5^{\prime \prime} \mathrm{O}\right)$, Lagoa do Cedro (1 $\left.5^{\circ} 53^{\prime} 49,7^{\prime \prime} \mathrm{S} ; 4^{\circ} 56^{\prime} 36,6^{\prime \prime O}\right)$, Lagoa Taquara $\left(15^{\circ} 38^{\prime} 12,4^{\prime \prime} S ; 47^{\circ} 31^{\prime} 22,0^{\prime \prime} \mathrm{W}\right)$ e

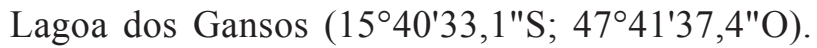
Todos localizam-se no Distrito Federal (DF), região central do Brasil, no Domínio Cerrado (figura 1). A região apresenta clima do tipo Aw (tropical chuvoso), segundo classificação de Köppen. A precipitação media anual é de aproximadamente $1.500 \mathrm{~mm}$, variando de $750 \mathrm{~mm}$ a $2.000 \mathrm{~mm}$ (Silva et al. 2008). Ocorrem duas estações bem definidas: uma quente e chuvosa, de outubro a março (temperatura média do ar em torno de $29{ }^{\circ} \mathrm{C}$ ), e uma fria e seca, de abril a setembro (temperatura média do ar em torno de $18^{\circ} \mathrm{C}$ ).

As cinco lagoas são ambientes rasos (profundidade, em geral, inferior a $3 \mathrm{~m}$ ), de área inferior a $1 \mathrm{~km}^{2}$, típicos de Cerrado, com águas oligotróficas (condutividade em geral inferior a $20 \mu \mathrm{S} \mathrm{cm}^{-1}$ ), levemente ácidas, e abundante flora de macrófitas aquáticas (ver Estrela et al. 2011). Todas elas integram a subbacia do Rio São Bartolomeu, que por sua vez faz parte da grande Bacia do Rio Paraná. A Lagoa Bonita localiza-se dentro da Estação Ecológica de Águas Emendadas; as demais, em áreas rurais. A Lagoa do Cedro é a que sofre maior influência antrópica dentre as lagoas, por ser de mais fácil acesso à população. Outras informações sobre ecossistemas aquáticos da região podem ser encontradas em Fonseca et al. (2014).

O levantamento taxonômico foi realizado com base na análise de 15 amostras provenientes de coletas nos anos de 2006, 2008 e 2009, em estações distintas (seca: agosto e setembro; chuvosa: março a maio). Ao todo, foram três amostras para cada lagoa (tabela 1).

As amostragens foram todas realizadas na zona litorânea, num único ponto para cada lagoa. O material perifítico foi obtido de diferentes tipos de substratos. Pedras e folhas foram escovadas e lavadas com água destilada, enquanto macrófitas foram espremidas ou escovadas. Ainda no campo, as amostras foram preservadas em solução aquosa de formalina com concentração final entre $3 \%$ e $5 \%$. A análise do material foi realizada no Laboratório de Botânica da Universidade Católica de Brasília, utilizando-se microscópio de marca Olympus modelo BX41 equipado com sistema de captura de imagens, sob aumentos de até $1000 \times$. Foram registradas as medidas celulares e características morfológicas.

O estudo taxonômico foi realizado a partir de análise populacional (cerca de 10 lâminas para cada amostra) na qual se observaram variações morfológicas com base em referências clássicas e/ ou recentes, tais como, Borge (1899, 1903, 1918, 1924), Förster (1964, 1969, 1974), Růžička (1981),

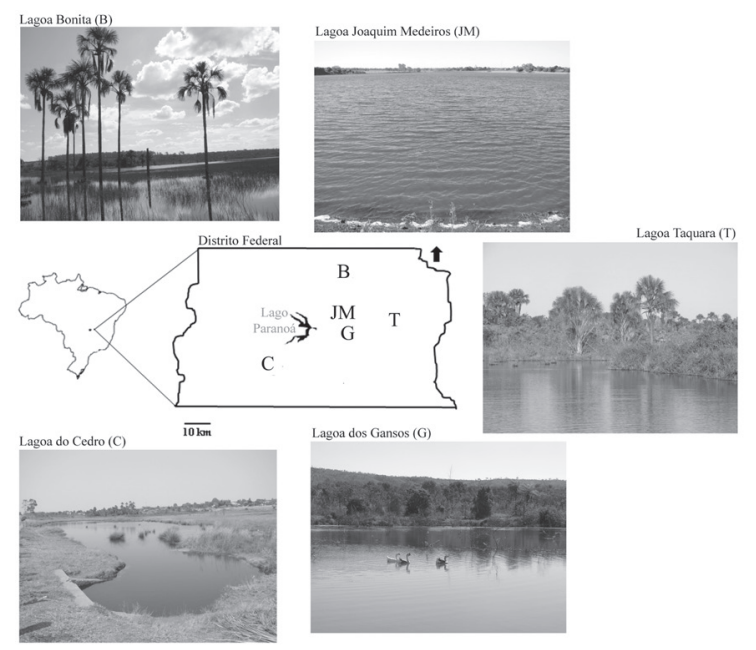

Figura 1. Mapa do Distrito Federal com a localização das cinco lagoas estudadas (B: Lagoa Bonita; JM: Lagoa Joaquim Medeiros; G: Lagoa dos Gansos; T: Lagoa Taquara; C: Lagoa do Cedro).

Figure 1. Map of the Federal District with location of the five studied lagoons (B: Lagoa Bonita; JM: Lagoa Joaquim Medeiros; G: Lagoa dos Gansos; T: Lagoa Taquara; C: Lagoa do Cedro). 
Lenzenweger (1996), Schetty (2002), Oliveira et al. (2009) e Felisberto \& Rodrigues (2008). Para cada indivíduo encontrado foram registradas medidas de comprimento (compr.), largura total (larg.) e largura do istmo (istmo). As amostras foram depositadas no Herbário da Universidade de Brasília (UB).

Os táxons de Euastrum foram classificados em pequenos (compr. $<50 \mathrm{~mm}$ ), médios (compr. 51-100 mm) e grandes (compr. $>100 \mathrm{~mm}$ ), de acordo com Schetty (2002).

\section{Resultados e Discussão}

Foram registrados 13 táxons de Euastrum, 11 de Micrasterias e um de Triploceras; destes, 12 são citações pioneiras para o DF (nove de Euastrum e três de Micrasterias) (tabela 2). Na descrição das espécies, tais táxons aparecem marcados com um asterisco. Considerando todo o período de estudo, a Lagoa dos Gansos apresentou o maior número de táxons (14). O gênero Euastrum foi registrado em todas as lagoas. O táxon mais comum foi Euastrum brasiliense var. brasiliense Borge, presente em todas as lagoas, com exceção da Lagoa Bonita. Por outro lado, na Lagoa Joaquim Medeiros não foi registrado nenhum táxon de Micrasterias, embora estudos anteriores realizados por Cronberg (1977) tenham encontrado os táxons M. laticeps, M. sol var. ornata e M. radiata var. brasiliense (tabela 3). Quanto a Triploceras, só foi encontrado na Lagoa Bonita. A relação dos táxons presentes em cada amostra encontra-se na tabela 2.

\section{Euastrum Ehrenberg ex Ralfs}

O gênero Euastrum caracteriza-se por células usualmente mais compridas do que largas, constrição mediana profunda, vista apical oval a elíptica. Cada semicélula costuma apresentar lobos laterais e apicais distintos, com uma incisão na região mediana do ápice bem característica. A parede celular pode ser desde lisa, com poros esparsos, a ornamentada com grânulos ou espinhos curtos. Normalmente há um cloroplasto por semicélula, com um ou mais pirenoides (Bicudo \& Menezes 2006, Guiry 2014).

Chave artificial para identificação das espécies e variedades de Euastrum:

1. Células com comprimento $<40 \mathrm{~mm}$

2. Semicélulas trapeziformes

3. Presença de pequenos espinhos nos ângulos dos lobos apicais E. rectangulare

3. Ausência de pequenos espinhos nos ângulos dos lobos apicais E. crassangulatum

2. Semicélulas piramidais

4. Semicélulas com margens laterais retas E. sublobatum var. kriegeri

4. Semicélulas com margens laterais apresentando ondulações E. cornubiense

1. Células com comprimento $\geq 40 \mathrm{~mm}$

5. Razão comprimento/largura $>2$ E. brasiliense var. brasiliense

5. Razão comprimento/largura $\leq 2$

6. Semicélulas trapeziformes

7. Presença de espinhos nos ângulos dos lobos

8. Lobos basais com apenas 1 ondulação proeminente

E. platycerum

8. Lobos basais com 2 ondulações proeminentes

9. Incisão profunda entre lobos basais e apicais E. spinulosum var. spinulosum

9. Incisão rasa entre lobos basais e apicais E. spinulosum var. eckertii

7. Ausência de espinhos nos ângulos dos lobos

10. Presença de 5 proeminências na face ventral das semicélulas

10. Ausência de 5 proeminências na face ventral das semicélulas

11. Ângulos dos lóbulos marcados por espessamentos E. cf. gemmatum var. gemmatum 11. Ângulos dos lóbulos sem espessamentos E. sinuosum var. sinuosum E. sinuosum var. subganense

6. Semicélulas piramidais

12. Ângulos dos lobos proeminentes E. didelta

12. Lobos com contornos suaves E. sp. 
Tabela 1. Táxons de Euastrum, Micrasterias e Triploceras em cinco lagoas do Distrito Federal, Brasil. *Primeira citação para o DF; S6: Seca de 2006; C8: chuva de 2008; S8: seca de 2008; C9: chuva de 2009.

Table 1. Taxa of Euastrum, Micrasterias, and Triploceras in five lagoons of the Federal District, Brazil. *First citation for the FD; S6: 2006 dry season; C8: 2008 rainy season; S8: 2008 dry season; C9: 2009 rainy season.

\begin{tabular}{|c|c|c|c|c|c|c|c|c|c|c|c|c|c|c|c|}
\hline \multirow[t]{2}{*}{ Táxons } & \multicolumn{3}{|c|}{$\begin{array}{l}\text { Lagoa } \\
\text { Bonita }\end{array}$} & \multicolumn{3}{|c|}{$\begin{array}{c}\text { Lagoa } \\
\text { Joaquim } \\
\text { Medeiros }\end{array}$} & \multicolumn{3}{|c|}{$\begin{array}{l}\text { Lagoa do } \\
\text { Cedro }\end{array}$} & \multicolumn{3}{|c|}{$\begin{array}{l}\text { Lagoa } \\
\text { Taquara }\end{array}$} & \multicolumn{3}{|c|}{$\begin{array}{c}\text { Lagoa dos } \\
\text { Gansos }\end{array}$} \\
\hline & S6 & $\mathrm{C} 8$ & C9 & S6 & $\mathrm{C} 8$ & $\mathrm{~S} 8$ & S6 & $\mathrm{C} 8$ & $\mathrm{~S} 8$ & S6 & $\mathrm{C} 8$ & S8 & $\mathrm{S} 6$ & $\mathrm{C} 8$ & S8 \\
\hline Euastrum brasiliense var. brasiliense Borge & & & & $\mathrm{X}$ & & & $\mathrm{X}$ & & & $\mathrm{X}$ & $\mathrm{X}$ & $\mathrm{X}$ & $\mathrm{X}$ & $\mathrm{X}$ & $\mathrm{X}$ \\
\hline * Euastrum cornubiense West \& G.S.West & & & & & & & $\mathrm{X}$ & & & & & & & & \\
\hline * Euastrum crassangulatum Børgesen & & & & & & & $\mathrm{X}$ & & & & & $\mathrm{X}$ & $\mathrm{X}$ & & $\mathrm{X}$ \\
\hline Euastrum didelta Turpin ex Ralfs & & & & $\mathrm{X}$ & $\mathrm{X}$ & $\mathrm{X}$ & & & & & & & & & $\mathrm{X}$ \\
\hline Euastrum cf. gemmatum var. gemmatum Ralfs & $\mathrm{X}$ & & $\mathrm{X}$ & & & & $\mathrm{X}$ & & & & $\mathrm{X}$ & & & & \\
\hline * Euastrum platycerum Reinsch & & & & $\mathrm{X}$ & & & & & & & & & & & \\
\hline * Euastrum rectangulare Fritsch \& M.F.Rich & & $\mathrm{X}$ & $\mathrm{X}$ & & & & & & & $\mathrm{X}$ & $\mathrm{X}$ & $\mathrm{X}$ & & & $\mathrm{X}$ \\
\hline $\begin{array}{l}\text { * Euastrum sinuosum var. sinuosum Lenormand } \\
\text { ex W.Archer }\end{array}$ & & & & $\mathrm{X}$ & $\mathrm{X}$ & $\mathrm{X}$ & & & & & & & & & $\mathrm{X}$ \\
\hline $\begin{array}{l}\text { * Euastrum sinuosum Lenormand ex W.Archer var. } \\
\text { subganense Förster }\end{array}$ & & $\mathrm{X}$ & $\mathrm{X}$ & & & & & & & & & & & & $\mathrm{X}$ \\
\hline * Euastrum spinulosum var. spinulosum Delponte & & & & $\mathrm{X}$ & & & & & & & & & & & \\
\hline $\begin{array}{l}\text { * Euastrum spinulosum Delponte var. eckertii } \\
\text { Förster }\end{array}$ & & & & & & & $\mathrm{X}$ & & & & & & $\mathrm{X}$ & & $\mathrm{X}$ \\
\hline $\begin{array}{l}\text { * Euastrum sublobatum var. kriegeri Cedercreutz } \\
\text { \& Gronblad }\end{array}$ & & & & $\mathrm{X}$ & $\mathrm{X}$ & $\mathrm{X}$ & & & & & & & & & \\
\hline Euastrum sp. & & & & & $\mathrm{X}$ & & & & & & & & & & $\mathrm{X}$ \\
\hline * Micrasterias arcuata Bailey var. robusta Borge & & & & & & & $\mathrm{X}$ & & & & & & & & \\
\hline $\begin{array}{l}\text { * Micrasterias arcuata Bailey var. subpinnatifida } \\
\text { West \& G.S. West }\end{array}$ & & & & & & & & & & & & & & & $\mathrm{X}$ \\
\hline Micrasterias borgei $\mathrm{H}$. Krieg. var. borgei & & & & & & & & & & & & & & & $\mathrm{X}$ \\
\hline $\begin{array}{l}\text { * Micrasterias denticulata var. denticulata } \\
\text { Brébisson ex Ralfs }\end{array}$ & & & & & & & & & & $\mathrm{X}$ & & $\mathrm{X}$ & & & \\
\hline Micrasterias furcata C. Agardh ex Ralfs & & $\mathrm{X}$ & & & & & & & & & & & $\mathrm{X}$ & & \\
\hline Micrasterias laticeps Nordstedt var. laticeps & & $\mathrm{X}$ & $\mathrm{X}$ & & & & & & & & & & $\mathrm{X}$ & & $\mathrm{X}$ \\
\hline Micrasterias pinnatifida (Kützing) ex Ralfs & & & $\mathrm{X}$ & & & & & & & & & & & & \\
\hline $\begin{array}{l}\text { Micrasterias radiosa Ralfs var. elegantior (G.S. } \\
\text { West) Croasdale }\end{array}$ & & & $\mathrm{X}$ & & & & & & & & & & & & \\
\hline $\begin{array}{l}\text { Micrasterias rotata (Grev.) Ralfs ex Ralfs var. } \\
\text { rotata }\end{array}$ & & & & & & & & & & & & & & & $\mathrm{X}$ \\
\hline $\begin{array}{l}\text { Micrasterias truncata (Corda) Bréb. ex Ralfs var. } \\
\text { pusilla } \text { G. S. West }\end{array}$ & $\mathrm{X}$ & $\mathrm{X}$ & $\mathrm{X}$ & & & & & & & & & & & & $\mathrm{X}$ \\
\hline Micrasterias sp. & & & & & & & & & & & & & $\mathrm{X}$ & & \\
\hline $\begin{array}{l}\text { Triploceras gracile Bailey var. bidentatum } \\
\text { (Nordstedt) Nordstedt }\end{array}$ & $\mathrm{X}$ & $X$ & $\mathrm{X}$ & & & & & & & & & & & & \\
\hline Total de táxons & 3 & 6 & 8 & 6 & 4 & 3 & 6 & 0 & 0 & 3 & 3 & 4 & 6 & 1 & 13 \\
\hline
\end{tabular}


Euastrum brasiliense var. brasiliense Borge, Arkiv für Botanik 1:112, pl. 5: fig. 1. 1903.

Figuras $2 \mathrm{a}-2 \mathrm{~b}$

Células médias, 2,3-2,5 vezes mais longas do que largas, constrição mediana profunda, seno fechado; semicélulas trapeziformes; lobos basais levemente arredondados, com 2 inflações discretas nos ângulos próximos ao istmo e a meia distância entre a base e o ápice da célula; lobo apical truncado; fenda apical mediana profunda e fechada. Parede celular pontuada. Compr. 81-93 $\mu \mathrm{m}$; larg. 35-40 $\mu \mathrm{m}$; istmo 12-15 $\mu \mathrm{m}$.

Distribuição geográfica: América do Sul, Europa (Guiry 2014). Estados do Brasil: Rio Grande do Sul (Borge 1903), Mato Grosso (Borge 1903, 1918, Freitas \& Loverde-Oliveira 2013), Goiás (Förster 1964), São Paulo (Marinho \& Sophia 1997, Schetty 2002); e no
Distrito Federal: Lagoa Bonita (Leite 1990).

Material examinado: BRASIL. Distrito Federal: Lagoa Joaquim Medeiros, 8-VIII-2006, L.M.B. Estrela \& B.M. Fonseca (UB1787); Lagoa do Cedro, 19-IX-2006, L.M.B. Estrela \& B.M. Fonseca (UB1779); Lagoa dos Gansos, 8-VIII-2006, L.M.B. Estrela \& B.M. Fonseca (UB1783); idem, 2-V-2008, L.M.B. Estrela \& B.M. Fonseca (UB1784); idem, 5-IX-2008, L.M.B. Estrela \& B.M. Fonseca (UB1785); Lagoa Taquara,15-VIII-2006, L.M.B. Estrela \& B.M. Fonseca (UB1791); idem, 6-V-2008, L.M.B. Estrela \& B.M. Fonseca (UB1792); idem, 29-VIII-2008, L.M.B. Estrela \& B.M. Fonseca (UB1793).

Os indivíduos amostrados estão de acordo com Borge (1903) e Förster (1964). Este foi o táxon mais frequente entre as amostras analisadas, não estando

Tabela 2. Táxons de Euastrum e Micrasterias já citados para o Distrito Federal, Brasil, não encontrados no presente estudo.

Table 2. Taxa of Euastrum and Micrasterias already found in the Federal District, Brazil, not reported in the present study.

\begin{tabular}{|c|c|}
\hline Táxon & Local e referência \\
\hline Euastrum ansatum cf. var. concavum & Rio e Reservatório do Descoberto (Oliveira 2004) \\
\hline Euastrum cf. denticulatum & Lagoa Bonita (Gomes 2007) \\
\hline Euastrum cuspidatum Wolle var. goyazense (Förster) Förster & Lagoa Bonita (Leite 1990) \\
\hline $\begin{array}{l}\text { Euastrum evolutum (Nordstedt) W. West \& G.S. West } \\
\text { var. perornatum Scott \& Croasdale }\end{array}$ & Lagoa Bonita (Leite 1990) \\
\hline Euastrum foersteri Scott \& Croasdale & Lagoa Bonita (Leite 1990) \\
\hline Euastrum informae Borge & Lagoa Bonita (Cronberg 1977) \\
\hline Euastrum pirassunungae Borge & Lagoa Bonita (Leite 1990) \\
\hline Micrasterias comperei & Fazenda Água Limpa (Ganem \& Senna 1984) \\
\hline Micrasterias crux-melitensis (Ehrenberg) Ralfs & Lago Paranoá (Oliveira \& Krau 1970) \\
\hline Micrasterias foliaceae Bailey ex Ralfs & Lagoa Bonita (Leite 1990, Gomes 2007) \\
\hline $\begin{array}{l}\text { Micrasterias furcata C. Agardh ex Ralfs var. groenbladii } \\
\text { (Croasdale) Förster }\end{array}$ & Lagoa Bonita (Leite 1990) \\
\hline Micrasterias radians Turner & $\begin{array}{l}\text { Lagoa Bonita (Leite 1990), Lago Paranoá } \\
\text { (Oliveira \& Krau 1970) }\end{array}$ \\
\hline Micrasterias radiata var. brasiliense Grönbl. & $\begin{array}{l}\text { Lagoa Bonita, Lagoa Joaquim I e II } \\
\text { (Cronberg 1977) }\end{array}$ \\
\hline Micrasterias radiata var. grönbladii Croasdale & Reservatório Santa Maria (Cronberg 1977) \\
\hline Micrasterias schweinfurthii Borge & Córrego Coqueiro (Oliveira \& Krau 1970) \\
\hline Micrasterias sol var. ornata Nordst & $\begin{array}{c}\text { Reservatório Santa Maria, Reservatório } \\
\text { Descoberto, Lagoa Joaquim I e II, Lagoa Formosa } \\
\text { (Cronberg 1977) }\end{array}$ \\
\hline Micrasterias subaequalis Grönblad & Lagoa Bonita (Leite 1990) \\
\hline $\begin{array}{l}\text { Micrasterias tetraptera W. West \& G.S. West var. spinulosa } \\
\text { Grönblad }\end{array}$ & Lagoa Bonita (Leite 1990) \\
\hline Micrasterias torrey Bailey var. curvata Krieger & Lagoa Bonita (Leite 1990) \\
\hline
\end{tabular}



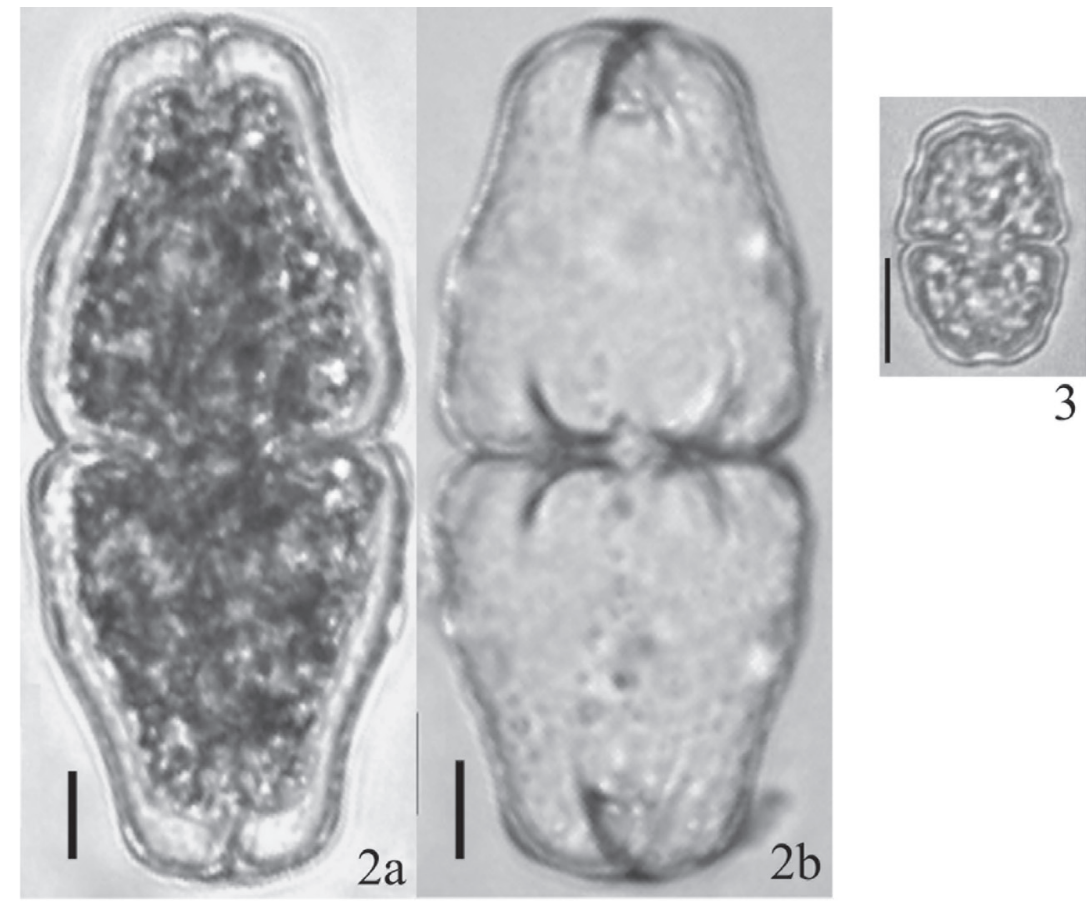

\section{3}

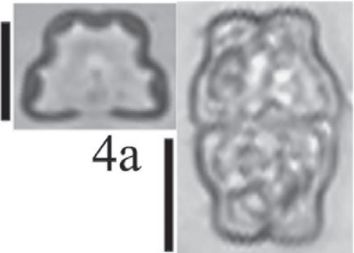

$4 \mathrm{~b}$

\section{$6 \mathrm{~b}$}
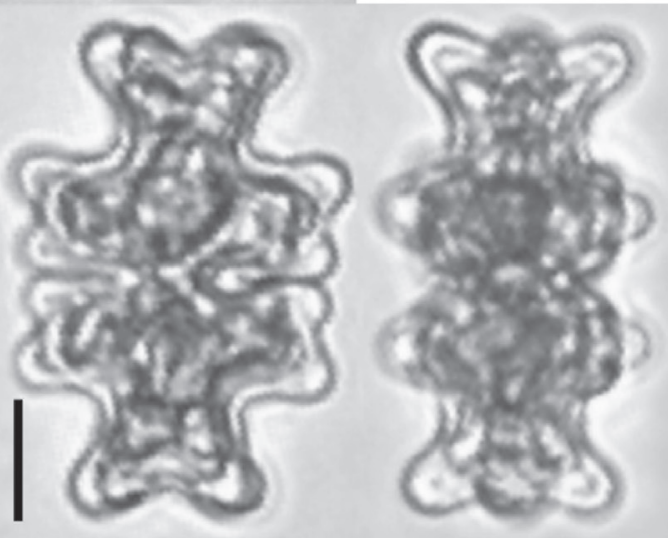

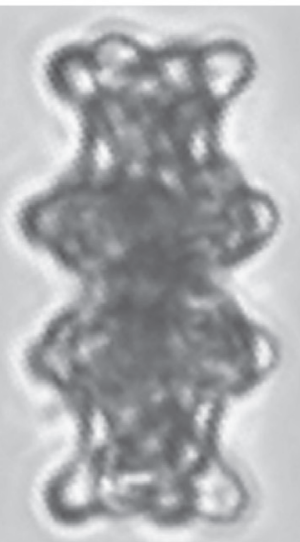

$6 a$

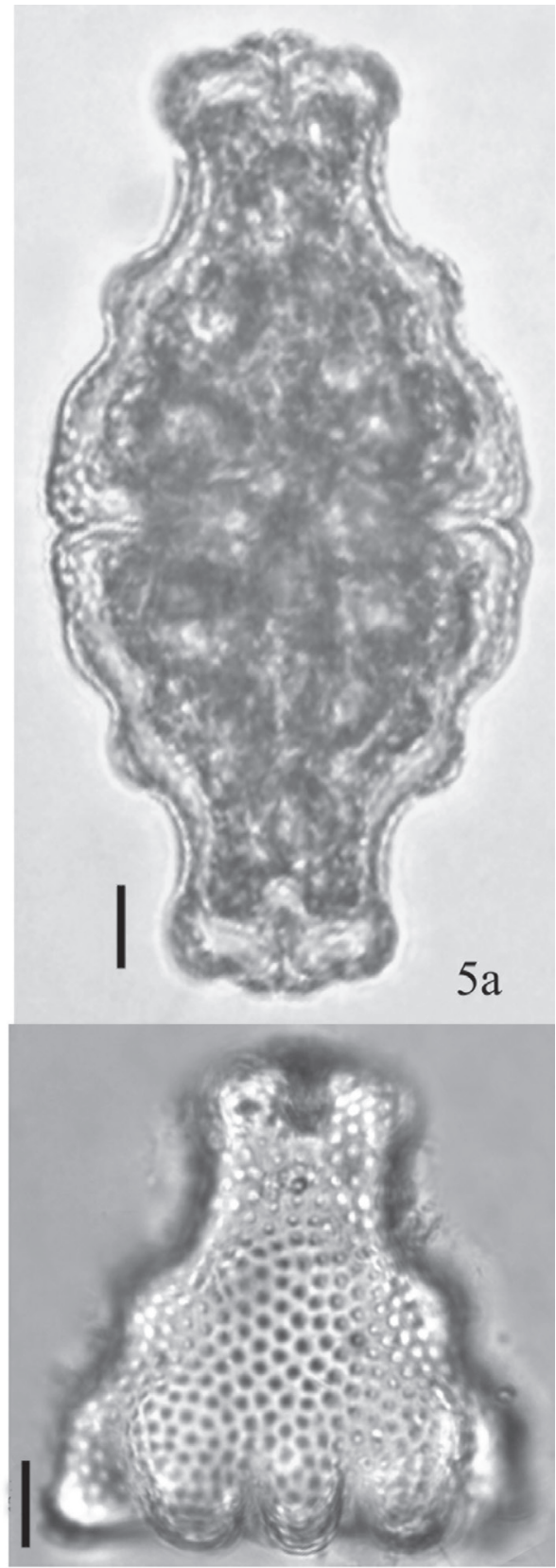

$5 b$

Figuras 2-6. 2 a-2 b. Euastrum brasiliense var. brasiliense. 2 a. Célula com cloroplasto; 2 b. Célula vazia. 3 . E. cornubiense. 4 a-4 b. E. crassangulatum. 4 a. Semicélula; 4 b. Indivíduo inteiro. 5 a-5 b. E. didelta. 5 a. Indivíduo inteiro; 5 b. Semicélula vazia destacando a ornamentação. 6 a-6 b. E. cf. gemmatum var. gemmatum. 6 a. Diferentes vistas de um mesmo indivíduo; 6 b. Semicélula vazia. (Barra da escala $=10 \mu \mathrm{m})$.

Figures 2-6. 2 a-2 b. Euastrum brasiliense var. brasiliense. 2 a. Cell with chloroplast; 2 b. Empty cell. 3 . E. cornubiense. 4 a-4 b. E. crassangulatum. 4 a. Semicell; 4 b. Entire individual. 5 a-5 b. E. didelta. 5 a. Entire individual; 5 b. Empty cell with ornamentation. 6 a-6 b. E. cf. gemmatum var. gemmatum. 6 a. Different views from the same individual; 6 b. Empty cell. $($ Scale bar $=10 \mu \mathrm{m})$. 
presente apenas na Lagoa Bonita, embora Leite (1990) o tenha registrado no local.

*Euastrum cornubiense West \& G.S.West, A Monograph of the British Desmidiaceae. II: 70, pl. 40: fig. 8. 1905.

Figura 3

Células pequenas, 1,5 vezes mais longa de larga, constrição mediana profunda, seno fechado; semicélulas piramidais, lobos basais com margens convergentes, com duas discretas ondulações; lobo apical arredondado, com ângulos bem marcados; fenda apical mediana rasa e aberta. Parede celular hialina. Compr. ca. $22 \mu \mathrm{m}$; larg. ca. $15 \mu \mathrm{m}$; istmo ca. $4 \mu \mathrm{m}$.

Distribuição geográfica: Europa (Růžička 1981), América do Norte, Caribe (Guiry 2014). Estado do Brasil: Goiás (Förster 1964).

Material examinado: BRASIL. Distrito Federal: Lagoa do Cedro, 19-IX-2006, L.M.B. Estrela \& B.M. Fonseca (UB1779).

Apesar de ter sido observado apenas um indivíduo, as características estiveram de acordo com Förster (1964) e (Růžička 1981). Primeira citação para o Distrito Federal.

*Euastrum crassangulatum Børgesen, Vidensk. Medd. Dansk. naturh. Foren. KBH., 37, pl. 3: fig. 25. 1891.

Figuras $4 \mathrm{a}-4 \mathrm{~b}$

Células pequenas, 1,5 vezes mais longas que largas, constrição mediana profunda, seno fechado; semicélulas trapeziformes, lobos basais arredondados; lobo apical truncado, com ângulos arredondados; fenda apical mediana rasa e aberta. Face das semicélulas com uma proeminência circular central e quatro outras menores, marginais. Parede celular hialina. Compr. 20-23 $\mu \mathrm{m}$; larg. 13-16 $\mu \mathrm{m}$; istmo 5-7 $\mu \mathrm{m}$.

Distribuição geográfica: Europa (Růžička 1981, Guiry 2014). Estado do Brasil: São Paulo (Schetty 2002).

Material examinado: BRASIL. Distrito Federal: Lagoa do Cedro, 19-IX-2006, L.M.B. Estrela \& B.M. Fonseca (UB1779), Lagoa dos Gansos, 8-VIII-2006, L.M.B. Estrela \& B.M. Fonseca (UB1783); idem, 5-IX-2008, L.M.B. Estrela \& B.M. Fonseca (UB1785); Lagoa Taquara, 29-VIII-2008, L.M.B. Estrela \& B.M. Fonseca (UB1793).

Indivíduos observados estão de acordo com Růžička (1981) e Lenzeweger (1996). Segundo este último autor, E. crassangulatum é uma espécie acidófila, observação coerente com as características limnológicas dos locais amostrados no presente estudo. Na Áustria tem sido registrada associada a musgos do gênero Sphagnum. Primeira citação para o Distrito Federal.

Euastrum didelta Turpin ex Ralfs, Brit. Desmidieae, 84, pl. XIV, fig. 1. 1848.

Figuras $5 \mathrm{a}-5 \mathrm{~b}$

Células grandes, 1,8-1,9 vezes mais longas do que largas, constrição mediana profunda, seno fechado; semicélulas piramidais, lobos basais arredondados, com um leve espessamento na margem dos ângulos; lobo apical truncado; fenda apical mediana profunda e fechada. Parede celular pontuada. Compr. (80-)100-110 $\mu \mathrm{m}$; larg. (43-)53-60 $\mu \mathrm{m}$; istmo (15-)25-35 $\mu \mathrm{m}$.

Distribuição geográfica: Cosmopolita (Guiry 2014). Estados do Brasil: São Paulo (Schetty 2002, como E. didelta var. quadriceps), Bahia (Oliveira 2011, como E. quadriceps), Goiás (Förster 1964, como E. quadriceps); e no Distrito Federal: Reservatório Torto (Cronberg 1977).

Material examinado: BRASIL. Distrito Federal: Lagoa Joaquim Medeiros, 8-VIII-2006, L.M.B. Estrela \& B.M. Fonseca (UB1787); idem, 25-IV-2008, L.M.B. Estrela \& B.M. Fonseca (UB1789); idem, 22-VIII-2008, L.M.B. Estrela \& B.M. Fonseca (UB1788); Lagoa dos Gansos, 5-IX-2008, L.M.B. Estrela \& B.M. Fonseca (UB1785).

Os indivíduos amostrados estão de acordo com Růžička (1981). Schetty (2002) citou E. didelta var. quadriceps em amostras do Estado de São Paulo e Förster (1964) apresentou o táxon E. quadriceps Nordst. como sinônimo de E. didelta var. quadriceps (Nordst.) Krieger em amostras coletadas no Estado de Goiás, todos com características muito semelhantes aos encontrados no presente estudo. Preferiu-se aqui manter a identificação apenas como E. didelta, pelo fato de as características que distinguem a var. quadriceps da variedade típica não estarem muito bem definidas na literatura consultada.

Euastrum cf. gemmatum var. gemmatum Ralfs, Brit. Desmidieae, 87, pl. XIV: fig. 4. 1848.

Figuras $6 \mathrm{a}-6 \mathrm{~b}$

Células pequenas, 1,5 vezes mais longas que largas, constrição mediana profunda, seno 
fechado; semicélulas trapeziformes, lobos basais retangulares em corte transversal, margens com dois lóbulos proeminentes. Lobo apical com margens laterais divergentes, terminando em ângulos bem arredondados; fenda apical mediana rasa e aberta. Presença de três ondulações na semicélula, duas próximas aos lobos basais e outra próxima ao lobo apical. Parede celular lisa. Compr. 41-43 $\mu \mathrm{m}$; larg. 27-30 $\mu \mathrm{m}$; istmo $8-9 \mu \mathrm{m}$.

Distribuição geográfica (Euastrum gemmatum): América do Sul, Europa (Guiry 2014). Estados do Brasil: São Paulo (Borge 1918), Goiás (Förster 1964), Amazonas (Förster 1969), Bahia (Oliveira 2009), Mato Grosso (Freitas \& Loverde-Oliveira 2013); e no Distrito Federal: Lagoa Bonita (Leite 1990).

Material examinado: BRASIL. Distrito Federal: Lagoa Bonita, 25-VIII-2006, L.M.B. Estrela \& B.M. Fonseca (UB1794); idem, 10-III-2009, L.M.B. Estrela \& B.M. Fonseca (UB1796); Lagoa do Cedro, 19-IX2006, L.M.B. Estrela \& B.M. Fonseca (UB1779); Lagoa Taquara, 6-V-2008, L.M.B. Estrela \& B.M. Fonseca (UB1792).

O material observado está de acordo com as ilustrações de E. gemmatum apresentadas por Borge (1918) e também por Förster $(1964,1969)$ a partir de material coletado nos Estados de Goiás e Amazonas. Entretanto, embora o formato da célula e as dimensões estejam de acordo com E. gemmatum, segundo alguns autores (Růžička 1981, Lenzenweger 1996) este táxon apresenta ornamentações nas semicélulas, normalmente na forma de verrugas, as quais não foram observadas neste estudo. Por isso a identificação foi mantida em conferatum.

*Euastrum platycerum Reinsch, Contributiones ad algologiam et fungologiam. Vol. 1. 85, pl. 12: fig. 6. 1875.

Figura 7

Células médias, 1,3 vezes mais longas do que largas, constrição mediana profunda, seno totalmente fechado a levemente aberto, acutangular; semicélulas trapeziformes, lobos basais com uma ondulação pronunciada que começa a meia distância do ápice, com ângulos adornados com grânulos; lobo apical truncado com ângulos arredondados também adornados com grânulos, margens laterais ligeiramente côncavas; fenda apical mediana rasa. Face das semicélulas adornadas com três círculos de grânulos, sendo um central e os outros dois laterais. Compr. ca. $70 \mu \mathrm{m}$; larg. ca. $52 \mu \mathrm{m}$; istmo ca. $9 \mu \mathrm{m}$.
Distribuição geográfica: Europa (Růžička 1981). Estados do Brasil: Mato Grosso (Freitas \& LoverdeOliveira 2013), Goiás (Förster 1964) e Bahia (Oliveira 2009), como E. platycerum var. groenbladii f. goyazense K.Förster \& F.Eckert.

Material examinado: BRASIL. Distrito Federal: BRASIL. Distrito Federal: Lagoa Joaquim Medeiros, 8-VIII-2006, L.M.B. Estrela \& B.M. Fonseca (UB1787).

Os indivíduos amostrados estão de acordo com Růžička (1981). Förster (1964) e Oliveira (2009) apresentam indivíduos identificados como E. platycerum var. groenbladii f. goyazense K.Förster \& F.Eckert com características idênticas aos observados no presente estudo. Como a diferenciação entre esta variedade e a típica não parecem claras na literatura, preferiu-se manter a identificação aqui dentro desta última. Observou-se certa sobreposição de características entre E. platycerum e E. spinulosum var. eckertii. A distinção entre estes táxons foi feita pelas diferenças nos senos e no formato dos lóbulos. E. platycerum apresenta seno fechado e lobo basal com apenas um ângulo (ver descrição de E. spinulosum var. eckertii mais adiante). Primeira citação para o Distrito Federal.

*Euastrum rectangulare Fritsch \& M.F.Rich, Trans. Roy. Soc. South Africa 25(2): 174, fig. 5M-N. 1937.

Figura 8

Células pequenas, 1,5 vezes mais longas do que largas, constrição mediana profunda, seno fechado; semicélulas sub-retangulares, ângulos dos lobos basais e apicais adornados com pequenos espinhos; lobo apical truncado; fenda apical mediana em "V". Compr. 18-22 $\mu \mathrm{m}$; larg. 11-15 $\mu \mathrm{m}$; istmo ca. $4 \mu \mathrm{m}$.

Distribuição geográfica: América do Sul (Guiry 2014). Estados do Brasil: Amazonas (Lopes \& Bicudo 2002), Bahia (Oliveira 2009, Santos et al. 2013), Paraná (Biolo et al. 2008), Mato Grosso (Freitas \& LoverdeOliveira 2013).

Material examinado: BRASIL. Distrito Federal: Lagoa Bonita, 27-V-2008, L.M.B. Estrela \& B.M. Fonseca (UB1795); idem, 10-III-2009, L.M.B. Estrela \& B.M. Fonseca (UB1796); Lagoa Taquara, 15-VIII2006, L.M.B. Estrela \& B.M. Fonseca (UB1791); idem, 6-V-2008, L.M.B. Estrela \& B.M. Fonseca (UB1792); idem, 29-VIII-2008, L.M.B. Estrela \& B.M. Fonseca (UB1793); Lagoa dos Gansos, 5-IX-2008, L.M.B. Estrela \& B.M. Fonseca (UB1785). 

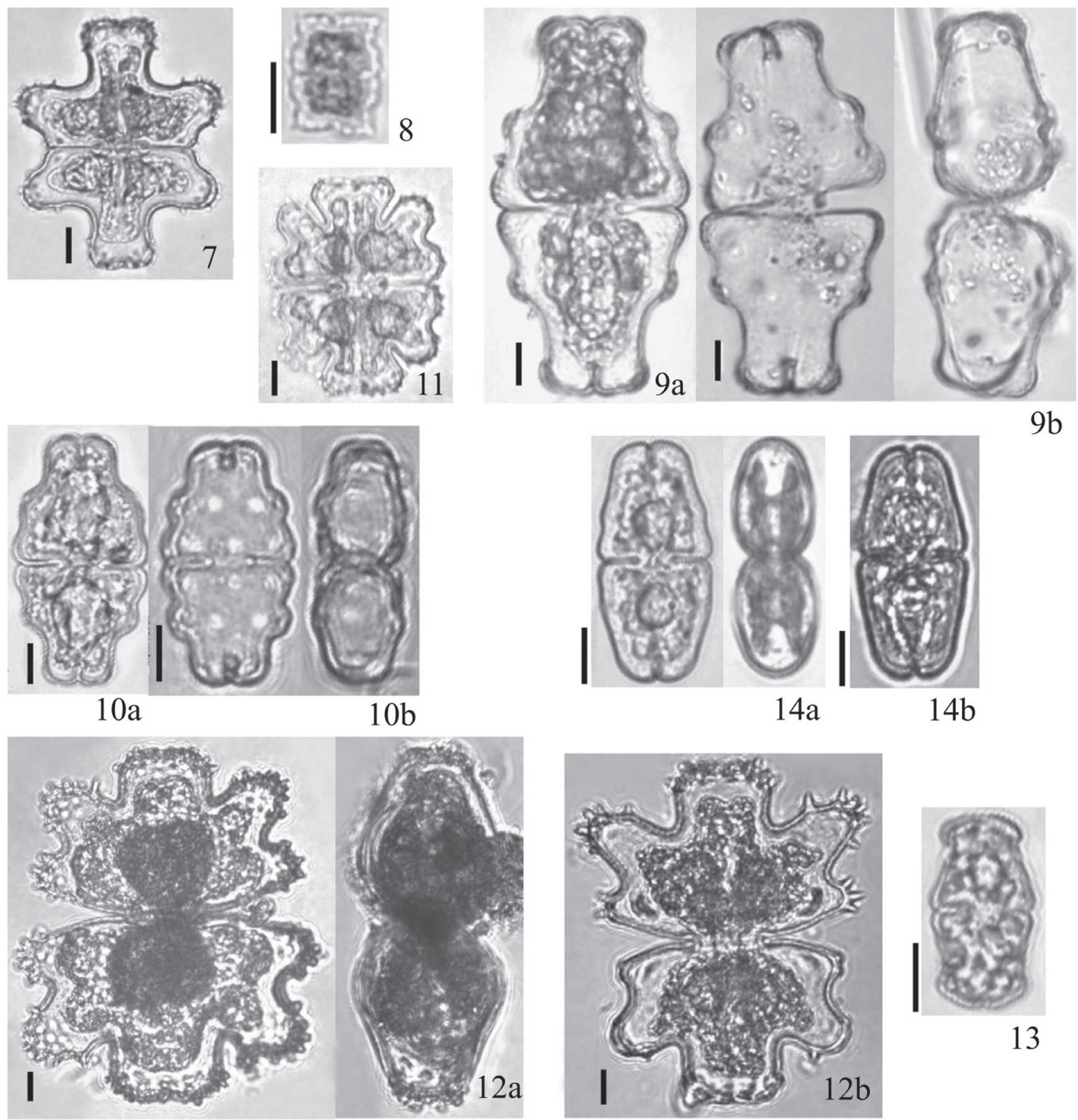

Figuras 7-14. 7. Euastrum platycerum. 8. E. rectangulare. 9 a-9 b. E. sinuosum var. sinuosum. 9 a. Célula com cloroplasto; 9 b. Célula vazia em vista frontal e lateral. 10 a-10 b. E. sinuosum var. subganense. 10 a. Célula com cloroplato; 10 b. Célula vazia em vista frontal e lateral. 11. E. spinulosum var. spinulosum. 12 a-12 b. E. spinulosum var. eckertii. 12 a. Indivíduo em vista frontal e lateral; 12 b. Variação morfológica. 13. E. sublobatum var. kriegeri. 14 a-14 b. E. sp. 14 a. Indivíduo em vista frontal e lateral; 14 b. Variação morfológica (Barra da escala $=10 \mu \mathrm{m})$.

Figures 7-14. 7. Euastrum platycerum. 8. E. rectangulare. 9 a-9 b. E. sinuosum var. sinuosum. 9 a. Cell with chloroplast; 9 b. Empty cell in frontal and lateral view. 10 a-10 b. E. sinuosum var. subganense. 10 a. Cell with chloroplast; 10 b. Empty cell in frontal and lateral view. 11. E. spinulosum var. spinulosum. 12 a-12 b. E. spinulosum var. eckertii. 12 a. Individual in frontal and lateral view; 12 b. Morphological variation. 13. E. sublobatum var. kriegeri. 14 a-14 b. E. sp. 14 a. Individual in frontal and lateral view; 14 b. Morphological variation. $($ Scale bar $=10 \mu \mathrm{m})$. 
Assemelha-se a E. gayanum de Toni (Růžička 1981), porém apresenta ângulos com margens mais retas. Primeira citação para o Distrito Federal.

*Euastrum sinuosum var. sinuosum Lenormand ex W.Archer. in Pritchard, A. (1861). A history of infusoria, including the Desmidiaceae and Diatomaceae, British and foreign, 729. 1861.

Figuras 9 a-9 b

Células médias, 1,8 vezes mais longas do que largas, constrição mediana profunda, seno fechado; semicélulas trapeziformes, lobos basais com duas ondulações; lobo apical truncado, com ângulos arredondados; fenda apical mediana profunda e fechada. As margens dos ângulos basais e apicais possuem um espessamento. Presença de cinco protuberâncias arredondadas na face das semicélulas. Parede celular pontuada. Compr. 70-74 $\mu \mathrm{m}$; larg. 7-40 $\mu \mathrm{m}$; istmo $10-11 \mu \mathrm{m}$.

Distribuição geográfica: Cosmopolita (Guiry 2014). Estados do Brasil: São Paulo (Borge 1918); Amazonas (Melo et al. 2009), Mato Grosso (Freitas \& LoverdeOliveira 2013).

Material examinado: BRASIL. Distrito Federal: Lagoa Joaquim Medeiros, 8-VIII-2006, L.M.B. Estrela \& B.M. Fonseca (UB1787); idem, 25-IV-2008, L.M.B. Estrela \& B.M. Fonseca (UB1789); idem, 22-VIII-2008, L.M.B. Estrela \& B.M. Fonseca (UB1788); Lagoa dos Gansos, 5-IX-2008, L.M.B. Estrela \& B.M. Fonseca (UB1785).

Os indivíduos observados estão de acordo com Borge (1918). De acordo com (Rủžička 1981), este táxon pode ter comprimento relativamente variável (de 50 a $90 \mathrm{~mm}$ ). Vários táxons infraespecíficos já foram propostos, muitos dos quais registrados no Brasil por Förster (1969, 1974), Oliveira (2009) e Schetty (2002). Primeira citação para o Distrito Federal.

*Euastrum sinuosum Lenormand ex W.Archer var. subganense Förster, Amazoniana II(1/2), Taf. 7, fig. 11-12. 1969.

Figuras $10 \mathrm{a}-10 \mathrm{~b}$

Células médias, 1,8 vezes mais longas do que largas, constrição mediana profunda, seno fechado; semicélulas trapeziformes, lobos basais com duas ondulações; lobo apical truncado, com ângulos arredondados; fenda apical mediana profunda e fechada. Presença de cinco protuberâncias arredondadas na face das semicélulas. Parede celular pontuada. Compr. $42-58 \mu \mathrm{m}$; larg. $24-32 \mu \mathrm{m}$; istmo 8-10 $\mu \mathrm{m}$.

Distribuição geográfica: Estado do Brasil: Amazonas (Förster 1969).

Material examinado: BRASIL. Distrito Federal: Lagoa Bonita, 27-V-2008, L.M.B. Estrela \& B.M. Fonseca (UB1795); idem, 10-III-2009, L.M.B. Estrela \& B.M. Fonseca (UB1796); Lagoa dos Gansos, 5-IX2008, L.M.B. Estrela \& B.M. Fonseca (UB1785).

Este táxon difere da variedade típica por não apresentar os espessamentos nas margens dos ângulos. Além disso, as dimensões são relativamente menores. Os indivíduos observados apresentaram as proeminências arredondadas nas semicélulas típicas da espécie, e estão de acordo com Förster (1969), apenas com dimensões menores (comprimento entre 67 a $74 \mu \mathrm{m}$, segundo este autor). Primeira citação para o Distrito Federal.

*Euastrum spinulosum var. spinulosum Delponte, Memorie della Reale Accademia delle Scienze di Torino, series 2 28: 97, pl. VI: figs 17, 18. 1876. Figura 11

Células médias, 1,2 vezes mais longas do que largas, constrição mediana profunda, seno fechado; semicélulas semicirculares, lobos basais com duas ondulações proeminentes, com ângulos ornados por grânulos; lobo apical truncado, com margens divergentes formando uma profunda invaginação com os lobos basais, ângulos arredondados também adornados por grânulos; fenda apical mediana rasa. Semicélulas adornadas por três círculos de grânulos, sendo um central e dois laterais. Compr. ca. $62 \mu \mathrm{m}$; larg. ca. $50 \mu \mathrm{m}$; istmo ca. $10 \mu \mathrm{m}$.

Distribuição geográfica: América do Sul, Europa, Ásia (Guiry 2014).

Material examinado: BRASIL. Distrito Federal: Lagoa Joaquim Medeiros, 8-VIII-2006, L.M.B. Estrela \& B.M. Fonseca (UB1787).

Foi observado apenas um indivíduo, identificado segundo Růžička (1981). Cronberg (1977) citou a variedade grandiornatum Förster para as Lagoas Joaquim I e II, Lagoa Bonita e Lagoa Feia, a qual difere da típica por apresentar incisões entre os lobos basais e apicais mais rasas e arredondadas; tal variedade foi descrita por Förster (1969) em material da Amazônia. Primeira citação para o Distrito Federal. 
*Euastrum spinulosum Delponte var. eckertii Förster, Desmidiaceen aus Brasilien, 1963.

Figuras $12 \mathrm{a}-12 \mathrm{~b}$

Células grandes, 1,6 vezes mais longas do que largas, constrição mediana profunda, seno aberto, acutangular; semicélulas semicirculares, lobos basais com duas ondulações proeminentes, com ângulos ornados por grânulos; lobo apical truncado, com margens laterais retas formando uma invaginação em "U" com os lobos basais, ângulos arredondados também adornados por grânulos; fenda apical mediana rasa. Semicélulas adornadas por três círculos de grânulos, sendo um central e dois laterais. Compr. 117-143 $\mu \mathrm{m}$; larg. 90-124 $\mu \mathrm{m}$; istmo 21-36 $\mu \mathrm{m}$.

Distribuição geográfica: Estado do Brasil: Goiás (Förster 1964).

Material examinado: BRASIL. Distrito Federal: Lagoa do Cedro, 19-IX-2006, L.M.B. Estrela \& B.M. Fonseca (UB1779); Lagoa dos Gansos, 8-VIII-2006, L.M.B. Estrela \& B.M. Fonseca (UB1783); idem, 5-IX-2008, L.M.B. Estrela \& B.M. Fonseca (UB1785).

Os indivíduos amostrados estão de acordo com Förster (1964). Táxon semelhante a E. spinulosum var. grandiornatum (Förster 1969), ou ainda a E. gemmatum Brébisson var. monocyclum Nordstedt, diferindo destes por apresentar seno aberto, característica constante em todos os indivíduos observados. Primeira citação para o Distrito Federal.

*Euastrum sublobatum Brébisson var. kriegeri Cedercreutz \& Gronblad. 3, pl. 2: fig. 35. 1936. Figura 13

Células pequenas, 1,9 vezes mais longas do que largas, constrição mediana profunda, seno fechado; semicélulas piramidais, margens laterais retas; lobo apical arredondado; fenda apical mediana rasa. Compr. 27-30 $\mu \mathrm{m}$; larg. 15-16 $\mu \mathrm{m}$; istmo 4-5 $\mu \mathrm{m}$.

Distribuição geográfica: Austrália e Nova Zelândia (Guiry 2014).

Material examinado: BRASIL. Distrito Federal: Lagoa Joaquim Medeiros, 8-VIII-2006, L.M.B.
Estrela \& B.M. Fonseca (UB1787); idem, 25-IV-2008, L.M.B. Estrela \& B.M. Fonseca (UB1789); idem, 22-VIII-2008, L.M.B. Estrela \& B.M. Fonseca (UB1788).

A identificação foi feita a partir de Růžička (1981, Tafel 74, fig. 13). Oliveira (2009) citou outras variedades da espécie em material do Estado da Bahia. Muito semelhante a E. bahiense, descrito por Förster (1964, pag. 349, pl. 4, fig. 15-17) a partir de amostras dos Estados da Bahia e Goiás. Primeira citação para o Distrito Federal.

\section{Euastrum sp.}

Figuras $14 \mathrm{a}-14 \mathrm{~b}$

Células médias, 2,2-2,3 vezes mais longas do que largas, constrição mediana profunda, seno fechado; semicélulas piramidais, margens laterais retas; lobo apical arredondado; fenda apical mediana rasa. Compr. 50-53 $\mu \mathrm{m}$; larg. 22-24 $\mu \mathrm{m}$; istmo 7-9 $\mu \mathrm{m}$.

Material examinado: BRASIL. Distrito Federal: Lagoa Joaquim Medeiros, 25-IV-2008, L.M.B. Estrela \& B.M. Fonseca (UB1789); Lagoa dos Gansos, 5-IX-2008, L.M.B. Estrela \& B.M. Fonseca (UB1785).

Os indivíduos observados apresentam certa semelhança morfológica com E. securiformiceps Borge var. goyazense Förster \& Eckert (Förster 1964, pag. 447, fig. 10). Porém a vista lateral elipsoide, sem nenhuma ornamentação ou protuberância, não corresponde a nenhum táxon observado na literatura consultada.

Micrasterias C. Agardh ex Ralfs

O gênero Micrasterias é formado por indivíduos usualmente solitários, achatados, com uma constrição mediana profunda. As semicélulas apresentam outras incisões, dividindo-as em dois lobos laterais e um apical os quais, por sua vez, podem também ser subdivididos em até quatro ordens (Škaloud et al. 2011). Várias espécies podem apresentar algum tipo de ornamentação como espinhos ou protuberâncias (Bicudo \& Menezes 2006, Guiry 2014).

Chave artificial para identificação das espécies e variedades de Micrasterias:

1. Células com comprimento $\leq 60 \mathrm{~mm}$

2. Lobos laterais com subdivisões M. truncata var. pusilla

2. Lobos laterais sem subdivisões

3. Extremidades dos lobos bifurcadas M. pinnatifida

3. Extremidades dos lobos não bifurcadas 
4. Célula mais comprida do que larga M. arcuata var. robusta

4. Célula tão comprida quanto larga M. arcuata var. subpinnatifida

1. Células com comprimento $>60 \mathrm{~mm}$

5. Lobos laterais sem subdivisões M. laticeps

5. Lobos laterais com subdivisões

6. Células de contorno arredondado

7. Lobos laterais subdivididos em até duas ordens

M. sp.

7. Lobos laterais subdivididos em mais de duas ordens

6. Células de contorno elíptico

8. Seno aberto, acutangular M. furcata

8. Seno fechado

9. Incisões nos lobos laterais fechadas em toda sua extensão M. denticulata

9. Incisões nos lobos laterais abertas pelo menos nas extremidades

10. Extremidades dos lobos terminando com espinhos de aproximadamente $5 \mathrm{~mm}$ de comprimento

M. rotata

10. Extremidades dos lobos terminando em espinhos curtos, com menos de $5 \mathrm{~mm}$ de comprimento ..... M. borgei var. borgei

*Micrasterias arcuata Bailey var. robusta Borge, Bihang Till K. Svenska Vet.-Akad. Handligar. Band 24, Afd. III, n. 12, Tab. 2, fig. 38-39. 1899.

Figura 15

Células com contorno elipsoide, constrição mediana rasa, acutangular; lobos basais sem incisões, com extremidades voltadas para o ápice, terminando com um dentículo; lobos apicais com pequena incisão mediana, presença de um dentículo nas extremidades; incisões interlobares amplas e arredondadas. Parede celular hialina; cloroplasto axial; pirenoides numerosos. Compr. ca. $38 \mu \mathrm{m}$; larg. ca. $31 \mu \mathrm{m}$; istmo ca. $10 \mu \mathrm{m}$.

Distribuição geográfica: Estados do Brasil: Goiás (Förster 1964), Amazonas (Förster 1969), Bahia (Oliveira et al. 2009).

Material examinado: BRASIL. Distrito Federal: Lagoa do Cedro, 19-IX-2006, L.M.B. Estrela \& B.M. Fonseca (UB1779).

Os indivíduos amostrados estão de acordo com Förster (1964). A variedade típica já foi citada para o Lago Paranoá (Giani 1984, Giani \& Pinto-Coelho 1986), Lagoas Joaquim I e II (Cronberg 1977) e Lagoa Bonita (Leite 1990). Estes dois últimos trabalhos também mencionaram as variedades compacta e expansa, respectivamente. Primeira citação para o Distrito Federal.

*Micrasterias arcuata Bailey var. subpinnatifida

West \& G.S. West, Journ. Bot. 35:86, pl. 366, fig.

7. 1897.

Figura 16
Células com contorno elipsoide a arredondado, constrição mediana rasa, seno acutangular; lobos basais sem incisões; lobos apicais com leve incisão mediana; incisões interlobares amplas, com lobo polar formando um "T". Parede celular hialina; cloroplasto axial; pirenoides numerosos. Compr. $42-51 \mu \mathrm{m}$; larg. 45-50 $\mu \mathrm{m}$; istmo ca. $10 \mu \mathrm{m}$.

Distribuição geográfica: Estado do Brasil: Goiás (Förster 1964), Bahia (Oliveira et al. 2009).

Material examinado: BRASIL. Distrito Federal: Lagoa dos Gansos, 5-IX-2008, L.M.B. Estrela \& B.M. Fonseca (UB1785).

Os indivíduos amostrados estão de acordo com Förster (1964). Primeira citação para o Distrito Federal.

Micrasterias borgei var. borgei H. Krieg, in Rabenhorst, Kryptogamen-Fl.Deutschl. 13(2):82, pl. 128, fig. 1-4. 1939.

Figura 17

Células com contorno elipsoide, constrição mediana profunda, fechada; semicélulas semicirculares; lobos laterais subdivididos em até três ordens, terminando em extremidades bifurcadas apresentando pequenos dentes; lobo apical com uma concavidade central, extremidades também bifurcadas, terminando com pequenos dentes; incisões interlobares profundas, acutangulares, quase fechadas. Parede celular hialina; cloroplasto axial; pirenoides numerosos. Compr. ca. $214 \mu \mathrm{m}$; larg. ca. $171 \mu \mathrm{m}$; istmo ca. $43 \mu \mathrm{m}$. 

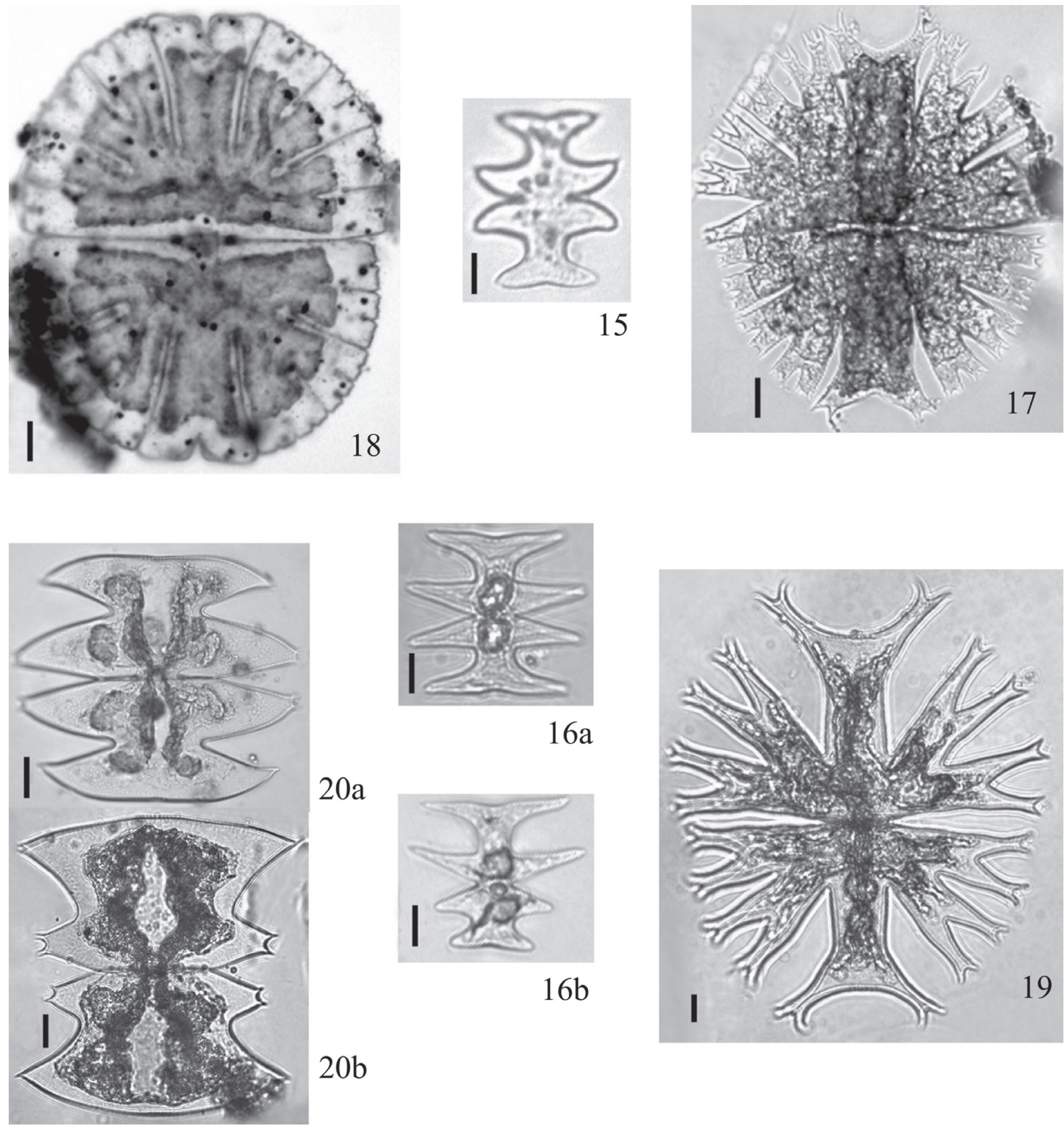

Figuras 15-20. 15. Micrasterias arcuata var. robusta. 16. M. arcuata var. subpinnatifida. 17. M. borgei var. borgei. 18. M. denticulate. 19. M. furcata. 20 a-20 b. M. laticeps var. laticeps. 20 b. Variação morfológica. (Barra da escala $=10 \mu \mathrm{m}$ para as figuras 15,16 e 19 ; $20 \mu \mathrm{m}$ para as figuras 17,18 e 20$)$.

Figures 15-20. 15. Micrasterias arcuata var. robusta. 16. M. arcuata var. subpinnatifida. 17. M. borgei var. borgei. 18. M. denticulate. 19. M. furcata. $20 \mathrm{a}-20$ b. M. laticeps var. laticeps. 20 b. Morphological variation. (Scale bar $=10 \mu \mathrm{m}$ for the figures 15, 16 and $19 ; 20 \mu \mathrm{m}$ for the figures 17,18 and 20). 
Distribuição geográfica: Estados do Brasil: Bahia (Oliveira et al. 2009), Mato Grosso (Freitas \& Loverde-Oliveira 2013); e no Distrito Federal: Lagoa Feia (Cronberg 1977).

Material examinado: BRASIL. Distrito Federal: Lagoa dos Gansos, 5-IX-2008, L.M.B. Estrela \& B.M. Fonseca (UB1785).

*Micrasterias denticulata var. denticulata Brébisson ex Ralfs, Brit. Desmidieae, 70, pl. VII, fig. 1. 1844. Figura 18

Células com contorno elipsoide, constrição mediana profunda, fechada; semicélulas semicirculares; incisões interlobares profundas, lobos laterais subdivididos em até três ordens, com incisões sempre fechadas, extremidades truncadas com leve invaginação central; lobo apical com incisão mediana em forma de "V", com ângulos arredondados. Parede celular hialina; cloroplasto axial; pirenoides

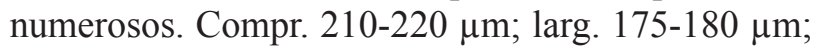
istmo ca. $11 \mu \mathrm{m}$.

Distribuição geográfica: Cosmpolita (Guiry 2014). Estados do Brasil: São Paulo (Sormus \& Bicudo 1997), Mato Grosso (Freitas \& Loverde-Oliveira 2013); Paraná (Aquino et al. 2014).

Material examinado: BRASIL. Distrito Federal: Lagoa Taquara, 15-VIII-2006, L.M.B. Estrela \& B.M. Fonseca (UB1791); idem, 29-VIII-2008, L.M.B. Estrela \& B.M. Fonseca (UB1793).

Os indivíduos amostrados estão de acordo com Růžička (1981), e foram registrados apenas na Lagoa Taquara. Primeira citação para o Distrito Federal.

Micrasterias furcata C. Agardh ex Ralfs, Brit. Desmidieae, 73, pl. 9, fig. 2. 1848. Figura 19

Células com contorno elipsoide, constrição mediana profunda, seno mediano aberto acutangular; semicélulas semicirculares; lobos laterais subdivididos em até duas ordens, com incisões amplamente abertas, cada lóbulo apresentando extremidade bifurcada, terminando com dois dentes; lobo apical formando um "T", com uma concavidade central, extremidades terminando com dois dentes; incisões interlobares profundas, acutangulares. Parede celular hialina; cloroplasto axial; pirenoides numerosos. Compr. 179-220 $\mu \mathrm{m}$; larg. 153-166 $\mu \mathrm{m}$; istmo 26-28 $\mu \mathrm{m}$.

Distribuição geográfica: Cosmopolita (Guiry 2014). Estados do Brasil: Goiás (Förster 1964 - como
M. radians var. brasiliense (Grönblad) Krieger), Amazonas (Lopes \& Bicudo 2002, Förster 1969 como M. radiata var. brasiliensis Grönblad), São Paulo (Taniguchi et al. 2000), Bahia (Oliveira et al. 2009, Santos et al. 2013), Paraná (Biolo et al., 2008, Bortolini et al., 2010), Mato Grosso (Freitas \& Loverde-Oliveira 2013); e no Distrito Federal (como M. radians): Lagoa Joaquim I e II (Cronberg 1977) e Lagoa Bonita (Leite 1990).

Material examinado: BRASIL. Distrito Federal: Lagoa dos Gansos, 8-VIII-2006, L.M.B. Estrela \& B.M. Fonseca (UB1783); Lagoa Bonita, 27-V-2008, L.M.B. Estrela \& B.M. Fonseca (UB1795).

A literatura aponta certa confusão taxonômica entre $M$. furcata, $M$. radians (especialmente a var. brasiliensis) e $M$. radiata, a qual foi bem discutida por Oliveira et al. (2009). O presente estudo acata a conclusão destes autores, assumindo-se o nome da espécie como $M$. furcata. O táxon é cosmopolita, e apresenta grande plasticidade morfológica.

Micrasterias laticeps var. laticeps Nordstedt, Vidensk. Medd. Dansk. naturh. Foren. 220, pl. II: fig. 14. 1870.

Figuras $20 \mathrm{a}-20 \mathrm{~b}$

Células com contorno aproximadamente retangular, constrição mediana profunda, seno mediano acutangular; semicélulas sub-retangulares; incisões interlobares acutangulares, lobos basais sem incisão, terminando com 1-2 pequenos dentes; lobo polar achatado, também terminando em um pequeno dente. Parede celular hialina; cloroplasto axial; pirenoides numerosos. Compr. ca. $157 \mu \mathrm{m}$; larg. ca. $149 \mu \mathrm{m}$; istmo ca. $21 \mu \mathrm{m}$.

Distribuição geográfica: Estados do Brasil: Amazonas (Förster 1969, Lopes \& Bicudo 2002), São Paulo (Taniguchi et al. 2000); Bahia (Oliveira et al. 2009), Paraná (Felisberto \& Rodrigues 2008, Biolo et al. 2008, Bortolini et al. 2010), Mato Grosso (Freitas \& Loverde-Oliveira 2013); e no Distrito Federal: Lagoa Joaquim I e II (Cronberg 1977) e Lagoa Bonita (Leite 1990).

Material examinado: BRASIL. Distrito Federal: Brasília: Lagoa dos Gansos, 8-VIII-2006, L.M.B. Estrela \& B.M. Fonseca (UB1783); idem, 5-IX-2008, L.M.B. Estrela \& B.M. Fonseca (UB1785); Lagoa Bonita, 27-V-2008, L.M.B. Estrela \& B.M. Fonseca (UB1795); idem, 10-III-2009, L.M.B. Estrela \& B.M. Fonseca (UB1796). 
Espécie com grande plasticidade morfológica (Bicudo \& Sormus 1972, Bicudo \& Senna 1975). Os indivíduos amostrados estão de acordo com Förster (1964). Cronberg (1977), em um trabalho realizado na Lagoa Joaquim I e II e no Reservatório de Santa Maria, citou duas variedades desta espécie; para os dois primeiros ambientes citados, a autora encontrou a variedade típica e para o reservatório, a variedade ampliata.

Micrasterias pinnatifida (Kützing) ex Ralfs, Brit.

Desmidieae, 77, pl. X: fig. 3. 1848.

Figura 21

Células com contorno elipsoide a arredondado, constrição mediana profunda, aberta nas extremidades, com seno acutangular; incisões amplamente abertas, lobos basais e apicais sem incisão, com extremidades bifurcadas; lobo polar com leve concavidade central. Parede celular hialina; cloroplasto axial. Compr. ca. $60 \mu \mathrm{m}$; larg. ca. $60 \mu \mathrm{m}$; istmo ca. $8 \mu \mathrm{m}$.

Distribuição geográfica: Cosmopolita (Guiry 2014). Estados do Brasil: Amazonas (Förster 1969), São Paulo (Sormus \& Bicudo 1997), Bahia (Oliveira et al. 2009), Mato Grosso (Freitas \& Loverde-Oliveira 2013); e no Distrito Federal: Lagoa Bonita (Leite 1990).

Material examinado: BRASIL. Distrito Federal: Brasília: Lagoa Bonita, 10-III-2009, L.M.B. Estrela \& B.M. Fonseca (UB1796).

Foi observado apenas um indivíduo, mas que apresentava as características típicas da espécie, segundo a literatura consultada.

Micrasterias radiosa Ralfs var. elegantior (G.S. West) H.T.Croasdale, In Prescott et al. Syn N. Amer. Desm. 2(2): 181, pl. 132, fig. 2-4. 1977.

Figura 22

Células com contorno circular, constrição mediana profunda, seno mediano acutangular, fechado nas extremidades externas; semicélulas semicirculares; lobos laterais subdivididos em até quatro ordens, terminando com dois dentes; lobo apical formando um " $T$ ", com concavidade no centro, extremidades terminando com 2-3 espinhos; incisões interlobares profundas, acutangulares. Parede celular hialina; cloroplasto seguindo o contorno da célula; pirenoides numerosos. Compr. ca. $170 \mu \mathrm{m}$; larg. ca. $170 \mu \mathrm{m}$; istmo ca. $25 \mu \mathrm{m}$.
Distribuição geográfica: Cosmopolita (Guiry 2014). Estados do Brasil: Amazonas (Förster 1969), Paraná (Felisberto \& Rodrigues 2008), Bahia (Oliveira et al. 2009), Mato Grosso (Freitas \& Loverde-Oliveira 2013); e no Distrito Federal: Reservatório Santa Maria (Cronberg 1977).

Material examinado: BRASIL. Distrito Federal: Brasília: Lagoa Bonita, 10-III-2009, L.M.B. Estrela \& B.M. Fonseca (UB1796).

Identificação de acordo com Růžička (1981). A variedade típica da espécie foi registrada no Distrito Federal para o Lago Paranoá (Oliveira \& Krau 1970) e Lagoa Bonita (Leite 1990).

Micrasterias rotata var. rotata (Grev.) Ralfs ex Ralfs, Annals Mag. Nat. Hist. 14:259, pl. 6, fig. 1. 1844. Figuras $23 \mathrm{a}-23 \mathrm{~b}$

Células com contorno elipsoide, constrição mediana profunda, fechada; semicélulas semicirculares; lobos laterais subdivididos em até três ordens, extreminados terminando com pequenos dentes; lobo apical com incisão mediana, extremidades também terminando com pequenos dentes; incisões interlobares profundas, fechadas. Parede celular hialina; cloroplasto axial; pirenoides numerosos. Compr. 280-354 $\mu \mathrm{m}$; larg. 286-300 $\mu \mathrm{m}$; istmo ca. $29 \mu \mathrm{m}$.

Distribuição geográfica: Cosmopolita (Guiry 2014). Estados do Brasil: São Paulo (Sormus \& Bicudo 1997), Paraná (Felisberto \& Rodrigues 2008, Biolo et al., 2008, Bortolini et al. 2010), Bahia (Oliveira et al. 2009), Mato Grosso (Freitas \& Loverde-Oliveira 2013); e no Distrito Federal: Reservatório Santa Maria (Cronberg 1977).

Material examinado: BRASIL. Distrito Federal: Lagoa dos Gansos, 5-IX-2008, L.M.B. Estrela \& B.M. Fonseca (UB1785).

Identificação de acordo com Růžička (1981).

Micrasterias truncata (Corda) Bréb. ex Ralfs var. pusilla G. S. West Mém. Soc. Neuchât. Sci. Nat. 2, 5:1035, pl. 22, fig. 42-43. 1914.

Figura 24

Célula com contorno aproximadamente circular, constrição mediana profunda, seno mediano acutangular; semicélulas sub-retangulares; lobos laterais subdivididos em até duas ordens, terminando com um pequeno dente; lobo polar truncado com uma 

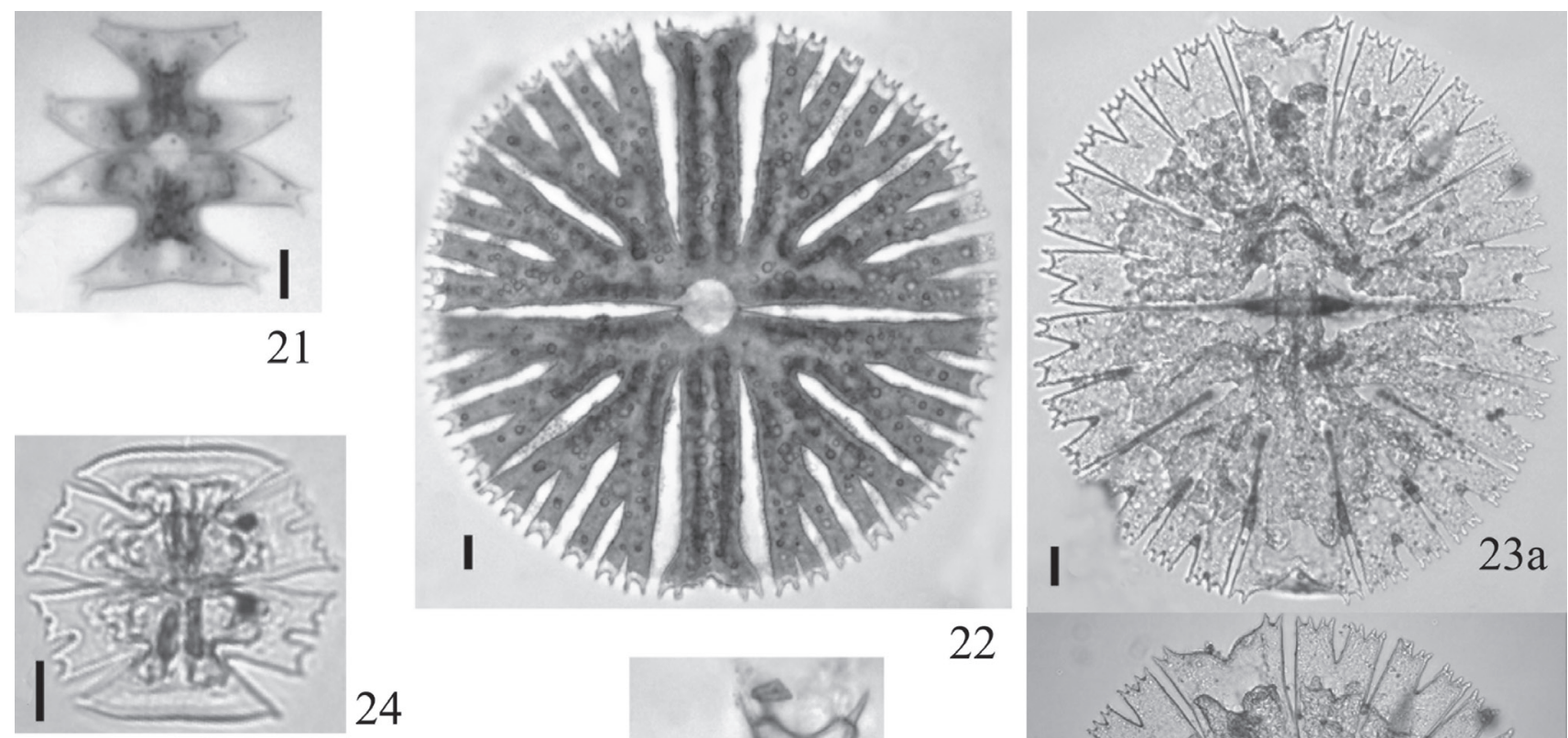

24
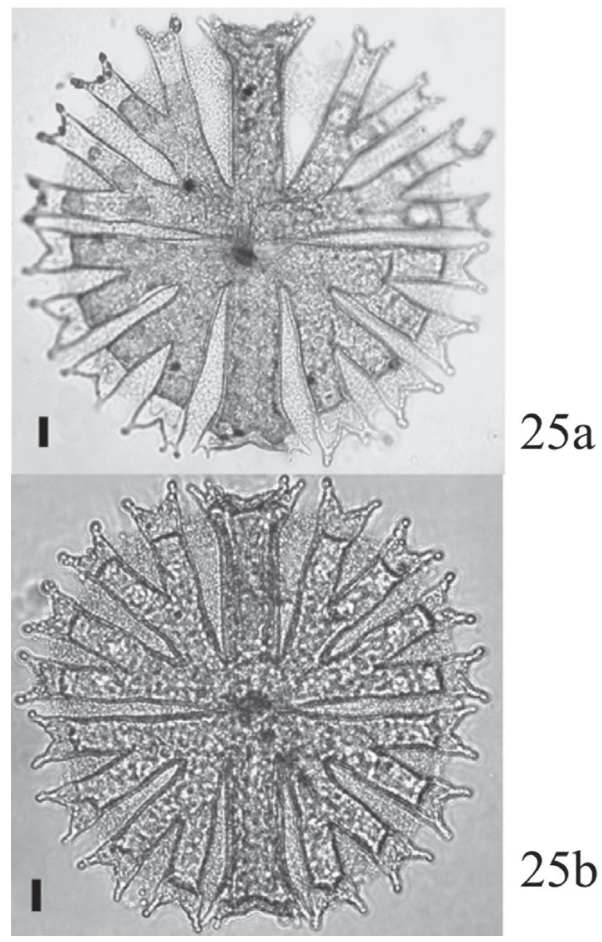

$25 b$

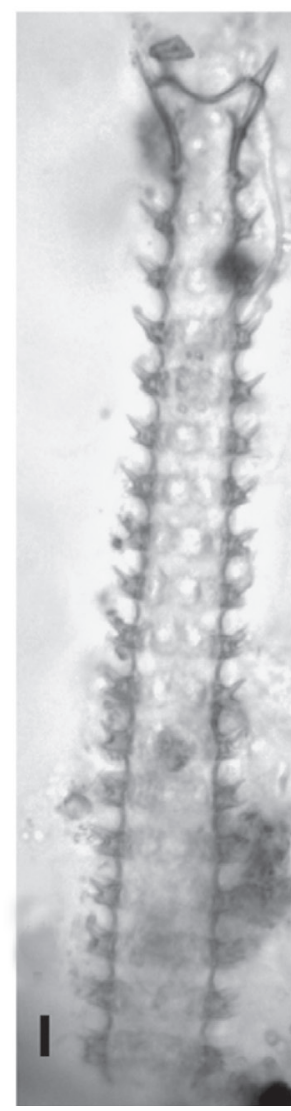

22
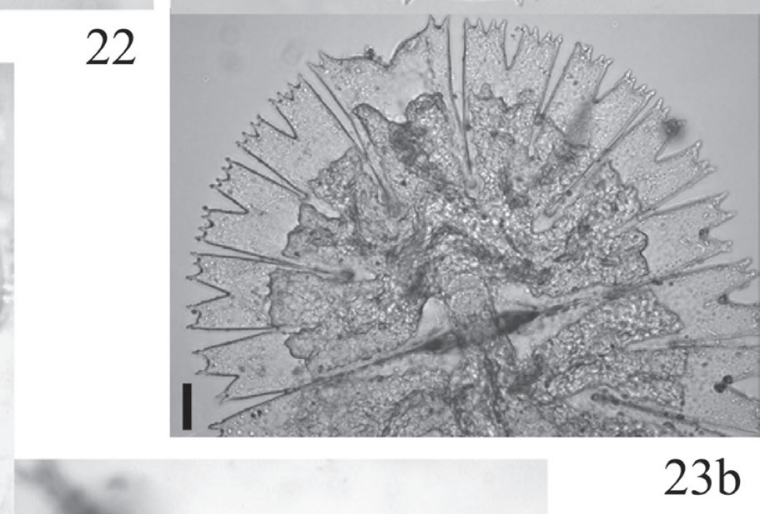

Figuras 21-26. 21. Micrasterias pinnatifida. 22. M. radiosa var. elegantior. 23a-23b. M. rotata var. rotata. 23a. Indivíduo inteiro; 23b. Detalhe da semicélula. 24. M. truncata var. pusilla. 25a-25b. M. sp. 26a-26b. Triploceras gracile var. bidentatum. 26a. Detalhe da semicélula; 26b. Indivíduo inteiro. (Barra da escala $=10 \mu \mathrm{m}$ para as figuras 21, 23b, 24, 25 e 26a; $20 \mu \mathrm{m}$ para as figuras 22, 23a e 26b).

Figures 21-26. 21. Micrasterias pinnatifida. 22. M. radiosa var. elegantior. 23a-23b. M. rotata var. rotata. 23a. Entire individual; 23b. Detail of the semicell. 24. M. truncata var. truncata. 25a-25b. M. sp. 26a-26b. Triploceras gracile var. bidentatum. 26a. Detail of the semicel; 26b. Entire individual. (Scale bar $=10 \mu \mathrm{m}$ for the figures 21, 23b, 24, 25 and 26a; $20 \mu \mathrm{m}$ for the figures 22, 23a, and 26b). 
leve concavidade central, também terminando em pequenos dentes; incisões interlobares abertas em "U". Parede celular hialina; cloroplasto axial; pirenoides numerosos. Compr. 47-50 $\mu \mathrm{m}$; larg. 47-52 $\mu \mathrm{m}$; istmo 8-10 $\mu \mathrm{m}$.

Distribuição geográfica: Cosmopolita (Guiry 2014). Estados do Brasil: São Paulo (Sormus \& Bicudo 1997), Rio Grande do Sul (Sophia et al. 2005), Bahia (Oliveira et al. 2009), Mato Grosso (Freitas \& Loverde-Oliveira 2013); e no Distrito Federal: Lago Paranoá (Oliveira \& Krau 1970), Lagoa Joaquim I e II e Lagoa Feia (Cronberg 1977), Lagoa Bonita (Leite 1990, Gomes 2007).

Material examinado: BRASIL. Distrito Federal: Brasília: Lagoa Bonita, 25-VIII-2006, L.M.B. Estrela \& B.M. Fonseca (UB1794); idem, 27-V-2008, L.M.B. Estrela \& B.M. Fonseca (UB1795); idem, 10-III-2009, L.M.B. Estrela \& B.M. Fonseca (UB1796); Lagoa dos Gansos, 5-IX-2008, L.M.B. Estrela \& B.M. Fonseca (UB1785).

M. truncata var. pusilla difere da variedade típica pelo formato mais arredondado e pelas dimensões menores (aproximadamente metade do tamanho).

\section{Micrasterias sp.}

Figura 25

Células com contorno circular, constrição mediana profunda, seno mediano aberto, acutangular; semicélulas semicirculares; lobos laterais subdivididos em até duas ordens, com incisões profundas, apresentando extremidade bifurcada, terminando com dois espinhos; lobo apical formando um "T", com concavidade no centro, extremidades terminando com dois espinhos; incisões interlobares profundas e abertas, acutangulares. Parede celular hialina; cloroplasto axial; pirenoides numerosos. Compr. 150-157 $\mu \mathrm{m}$; larg. 147-174 $\mu \mathrm{m}$; istmo $25-30 \mu \mathrm{m}$.

Material examinado: BRASIL. Distrito Federal: Brasília: Lagoa dos Gansos, 8-VIII-2006, L.M.B. Estrela \& B.M. Fonseca (UB1783).

Os indivíduos encontrados assemelham-se a M. radiosa Ralfs, porém diferem por apresentar um nível a menos de incisões no lóbulos. Esteve presente apenas nas amostras da Lagoa dos Gansos. Não foi encontrado na literatura nenhum táxon com características semelhantes.

\section{Triploceras Bailey}

Triploceras Bailey é formado por células solitárias, cilíndrico-alongadas com constrição mediana rasa. As semicélulas possuem vários aneis de protuberâncias portando um ou mais espinhos curtos. A extremidade das células é truncada, 2-4-furcadas, usualmente com dois espinhos em cada processo apical. Um cloroplasto axial por semicélula, estrelado em vista apical, com uma fileira de pirenoides.

Triploceras gracile Bailey var. bidentatum (Nordstedt)

Nordstedt, Bot. Not. 1887: 163. 1887.

Figuras $26 \mathrm{a}-26 \mathrm{~b}$

Células 12-14 vezes mais longas do que largas, cilíndricas, porém nitidamente atenuadas para as extremidades, pouco constritas na parte mediana da célula, seno aberto e raso; presença de 10-14 aneis de espinhos bifurcados, extremidades com 2 espinhos bifurcados. Compr. ca. $550 \mu \mathrm{m}$; larg. ca. $50 \mu \mathrm{m}$; istmo ca. $25 \mu \mathrm{m}$.

Distribuição geográfica: Oceania (Guiry 2014), Europa e América do Norte (segundo revisão de Oliveira et al. 2014), Paraguai (Borge 1903). Estados do Brasil: São Paulo (Borge 1918, Marinho \& Sophia 1997), Amazonas (Förster 1969), Bahia (Oliveira et al. 2014); e no Distrito Federal: Reservatório do Torto (Cronberg 1977), Lagoa Bonita (Leite 1990, Gomes 2007).

Material examinado: BRASIL. Distrito Federal: Brasília: Lagoa Bonita, 25-VIII-2006, L.M.B. Estrela \& B.M. Fonseca (UB1794); idem, 27-V-2008, L.M.B. Estrela \& B.M. Fonseca (UB1795); idem, 10-III-2009, L.M.B. Estrela \& B.M. Fonseca (UB1796).

Dentre as lagoas analisadas neste estudo, este táxon foi observado apenas na Lagoa Bonita. A identificação está de acordo com Förster (1969) e Oliveira et al. (2014).

Como comentários finais, destaca-se a contribuição deste estudo para o conhecimento da distribuição de Euastrum no Distrito Federal, considerando-se que $70 \%$ dos táxons encontrados ainda não haviam sido registrados na região. Por outro lado, alguns táxons de Micrasterias, anteriormente citados para a Lagoa Bonita, não foram encontrados nas amostras analisadas aqui. Esta Lagoa foi a mais rica entre as demais com relação ao gênero Cosmarium, segundo levantamento de Estrela et al. (2011), e esperava-se que o mesmo se repetisse para os gêneros de desmídias considerados aqui. Entretanto, embora Triploceras tenha sido observado exclusivamente na Lagoa Bonita, a maior riqueza tanto para Euastrum quanto para Micrasterias foi registrada na Lagoa dos Gansos, área de campo 
úmido até então nunca estudada. Outros trabalhos atualmente em andamento sobre a distribuição destes gêneros em ambientes naturais do Cerrado do Distrito Federal e entorno irão permitir um quadro mais amplo sobre sua ocorrência na região central do país.

\section{Agradecimentos}

Agradecemos ao Fundo Nacional do Meio Ambiente, pelo financiamento dado ao projeto "Restabelecimento da Integridade Ecológica e Ecogestão nas Bacias do São Francisco e Paranoá, DF" no qual este estudo esteve inserido; à Universidade Católica de Brasília, pela bolsa de Iniciação Científica concedida à segunda Autora; à Dra. Maria das Graças Machado de Souza (UnB), pelas valiosas dicas e sugestões; ao GEEA (Grupo de Estudos de Ecossistemas Aquáticos - Universidade Católica de Brasília), pelo apoio nas coletas.

\section{Literatura citada}

Abreu, C.T. 2001. Estudo do fitoplâncton ao longo de um sistema de córrego e represas nas estações de chuva e de seca, Rio Descoberto, DF. Dissertação de Mestrado, Universidade de Brasília, Brasília.

Aquino, C.A.N., Bueno, N.C. \& Menezes, V.C. 2014. Desmidioflórula (Zygnemaphyceae, Desmidiales) do rio Cascavel, Oeste do Estado do Paraná, Brasil. Hoehnea 41: 365-392.

Bicudo, C.E.M. \& Sormus, L. 1972. Polymorphism in the desmid Micrasterias laticeps and its taxonomical implications. Journal of Phycology 8:237-242.

Bicudo, C.E.M. \& Senna, P.A.C. 1975. Use of measurements for differentiation of infraspecific taxa in Micrasterias laticeps. British Phycological Journal 10: 43-47.

Bicudo, C.E.M. \& Menezes, M. 2006. Gêneros de Algas de Águas Continentais do Brasil - Chave para identificação e descrições. Editora RIMA, São Carlos.

Biolo, S., Siqueira, N.S. \& Bueno, N.C. 2008. Desmidiaceae (exceto Cosmarium) de um tributário do Reservatório de Itaipu, Paraná, Brasil. Hoehnea 35: 309-326.

Borge, O. 1899. Ueber tropische und subtropische. Süsswasser-Chlorophyceen. Bihang Till K. Svenska Vetenskaps-akademiens. Handlingar, Band 24, Afd. III, 12: 1-33.

Borge, O. 1903. Die Algen der ersten Regnellschen Expedition. II. Desmidiaceen. Arkiv för Botanik, Band 1: 71-138.

Borge, O. 1918. Die von Dr. A. Löfgren in São Paulo gessammelten Süsswasseralgen. Arkiv för Botanik, Band 15, 13: 1-103.
Borge, O. 1924. Die von Dr. F. C. Hoehne während der Expedition Roosevelt-Rondon gesammelten Süsswasseralgen. Arkiv för Botanik, Band 19, 17: 1-56.

Bortolini, J.C., Meurer, T., Bueno, N.C. 2010. Desmidiaceae (exceto Cosmarium) de um tributário do Reservatório de Itaipu, Paraná, Brasil. Hoehnea 37: 293-313.

Cronberg, G. 1977. The Lago Paranoá Restoration Project: Phytoplankton Ecology and Taxonomy. Final Report. Project PAHO/WHO/77/WT/BRA/2341/04.

Estrela, L.M.B., Fonseca, B.M. \& Bicudo, C.E.M. 2011. Desmídias Perifíticas de Cinco Lagoas do Distrito Federal, Brasil: I - Gênero Cosmarium Corda ex Ralfs. Hoehnea 38: 527-552.

Felisberto, S.A \& Rodrigues, L. 2008. Desmidiaceae, Gonatozygaceae e Mesotaeniaceae na comunidade perifítica do reservatório de Salto do Vau (Bacia do rio Iguaçu, PR). Hoehnea 35: 235-254.

Fonseca, B.M., Mendonça-Galvão, L., PadovesiFonseca, C., Abreu, L.M. \& Fernandes, A.C.M. 2014. Nutrient baselines of Cerrado low-order streams: comparing natural and impacted sites in the Central Brazil. Environmental Monitoring and Assessment 186: 19-36.

Förster, K. 1964. Desmidiaceen aus Brasilien. 2. Teil: Bahia, Goyaz, Piauhy und Nord-Brasilien. Hydrobiologia XXIII(3-4): 321-505.

Förster, K. 1969. Amazonische Desmidieen. 1. Teil: Areal Santarém. Amazoniana, II: 5-232.

Förster, K. 1974. Amazonische Desmidieen. 2. Teil: Areal Maués - Abacaxis. Amazoniana, 2: 135-242.

Freitas, L.C. \& Loverde-Oliveira, S.M. 2013. Checklist of green algae (Chlorophyta) for the state of Mato Grosso, Central Brazil. Check List 9: 1471-1483.

Giani, A. 1984. Distribuição horizontal do fitoplâncton e zooplâncton no Lago Paranoá. Dissertação de Mestrado, Universidade de Brasília, Brasília.

Giani, A. \& Pinto-Coelho, R.M. 1986. Contribuição ao conhecimento das algas fitoplanctônicas do reservatório do Paranoá, Brasília, Brasil: Chlorophyta, Euglenophyta, Pirrophyta e Schizophyta. Revista Brasileira de Botânica 9: 45-62.

Gomes, P.P. 2007. Variação espacial e temporal da comunidade fitoplanctônica da Lagoa Bonita, DF. Dissertação de Mestrado, Universidade de Brasília, Brasília.

Guiry, M.D. 2014. AlgaeBase. World-wide electronic publication, National University of Ireland, Galway. In: M.D. Guiry, G.M. Guiry, G.M. Disponível em http:// www.algaebase.org (acesso em 11-X-2014).

Leite, A.L.T. 1990. Desmidiaceae (Chlorophyta) e os fatores físico-químicos da Lagoa Bonita, Distrito Federal, Brasil. Dissertação de Mestrado, Universidade de Brasília, Brasília. 
Leliaert, F., Smith, D.R., Moreau, H., Herron, M.D., Verbruggen, H., Delwiche, C.F. \& De Clerck, O. 2012. Phylogeny and Molecular Evolution of the Green Algae. Critical Reviews in Plant Sciences 31: 1-46.

Lenzenweger, R. 1996. Desmidiaceeflora von Österreich. Teil 1. Bibliotheca Phycologica 101: 1-162.

Lopes, M.R.M. \& Bicudo, C.E.M. 2002. Desmidioflórula de um lago da planície de inundação do Rio Acre, Estado do Amazonas, Brasil. Acta Amazonica 33: 167-212.

Marinho, M.M. \& Sophia, M.G. 1997. Desmidioflórula do açude do Jacaré, município de Moji-Guaçu, SP, Brasil. Hoehnea 24: 37-53.

Melo, S., Souza, K.F., Rebelo, S.R.M. \& Sophia, M.G. 2009. Gêneros Euastrum Ehrenberg ex Ralfs e Micrasterias C. Agardh (ConjugatophyceaeDesmidiaceae) de dois ambientes amazônicos de águas pretas (Manaus, Amazonas-Brasil). Acta Amazonica 39: $13-20$

Mendonça-Galvão, L. 2005. Comunidade planctônica e o processo de restauração do Lago Paranoá, DF. Tese de Doutorado, Universidade de Brasília, Brasília.

Murakami, E.A. 2000. Variação sazonal do fitoplâncton e de algas epífitas associadas aos bancos de Polygonum ferrugineum Weed na Represa do Rio Descoberto, DF. Dissertação de Mestrado, Universidade de Brasília, Brasília.

Oliveira, E.C.A. 2004. Comunidades fitoplanctônicas em ambientes lêntico e lótico na Bacia do Rio Descoberto, DF, em períodos de chuva e seca. Dissertação de Mestrado, Universidade de Brasília, Brasília.

Oliveira, L.P.H. \& Krau, L. 1970. Hidrobiologia geral aplicada particularmente a veiculadores de esquistossomos - hipereutrofia, mal moderno das águas. Memórias do Instituto Oswaldo Cruz 68: 89-118.

Oliveira, I.B. 2011. Zygnematophyceae (Streptophyta) da Área de Proteção Ambiental Litoral Norte, Bahia, Brasil. Tese de Doutorado, Universidade Estadual de Feira de Santana, Feira de Santana.
Oliveira, I.B., Bicudo, C.E.M. \& Moura, C.W.N. 2014. Desmids (Desmidiaceae, Zygnemaphyceae) with cylindrical morphologies in the coastal plains of northern Bahia, Brazil. Acta Botanica Brasilica 28: 17-33.

Oliveira, I.B., Moura, C.W.N. \& Bicudo, C.E.M. 2009. Micrasterias C. Agardh ex Ralfs (Zygnemaphophyceae) de duas Áreas de Proteção Ambiental da planície litorânea do norte da Bahia, Brasil. Revista Brasileira de Botânica 32: 213-232.

Philomeno, M.G. 2007. A comunidade fitoplanctônica e a restauração do Lago Paranoá, Brasília, DF. Tese de Doutorado, Universidade de Brasília, Brasília.

Růžička, J. 1981. Die Desmidiaceen Mitteleuropas. Band 1, 1 Lieferung. E. Schweizerbart'sche Verlagsbuchhandlung. Stuttgart, Alemanha.

Santos, M.A., Conceição, L.P., Pereira, F.A., Oliveira, I.B. \& Santos, A.K.A. 2013. Desmidiaceae (Zygnematophyceae, Streptophyta) da Lagoa das Bateias, Vitória da Conquista, Bahia, Brasil. Sitientibus. Série Ciências Biológicas 13: 1-13.

Schetty, S. 2002. O gênero Euastrum (Zygnematophyceae) no Estado de São Paulo: levantamento florístico. Dissertação de Mestrado, Universidade de São Paulo, Ribeirão Preto.

Silva, F.A.M. da, Assad, E.D. \& Evangelista, B.A. 2008. Caracterização climática do bioma Cerrado. In: S.M. Sano, S.M.P. Almeida \& J.F. Ribeiro (eds.). Cerrado: Ecologia e Flora. Embrapa Informação Tecnológica, Brasília, pp. 69-87.

Škaloud, P., Nemjová, K., Veselá, J., Černá, K. \& Neustupa, J. 2011. A multilocus phylogeny of the desmid genus Micrasterias (Streptophyta): evidence for the accelerated rate of morphological evolution in protists. Molecular Phylogenetics and Evolution 61: 933-943.

Taniguchi, G.M., Senna, P.A.C., Compère, P. 2000. Desmídias (Conjugatophyceae) ocorrentes em um banco de macrófitas aquáticas da Lagoa do Diogo 2. Família Desmidiaceae (tripos Euastreae, Xanthideae, Staurastreae e Hyalotheceae). In: J.E. Santos \& J.S.R. Pires (eds.). Estudos integrados em ecossistemas 2. Estação Ecológica de Jataí. Ed. RIma, São Carlos, pp. 457-467. 